\title{
TITLE:
}

\section{The nuclear field shift effect in chemical exchange reactions}

$\operatorname{AUTHOR}(\mathrm{S}):$

Fujii, Toshiyuki; Moynier, Frédéric; Albarède, Francis

\section{CITATION:}

Fujii, Toshiyuki ...[et al]. The nuclear field shift effect in chemical exchange reactions. Chemical Geology 2009, 267(3-4): 139-156

\section{ISSUE DATE:}

2009-09

URL:

http://hdl.handle.net/2433/86911

\section{RIGHT:}

c 2009 Elsevier B.V. All rights reserved.; この論文は出版社版でありませ ん。引用の際には出版社版をご確認ご利用ください。; This is not the published version. Please cite only the published version. 
1 The Nuclear Field Shift Effect in Chemical Exchange Reactions

2

3 Toshiyuki Fujii ${ }^{a}$, Frédéric Moynier ${ }^{b}$, Francis Albarède ${ }^{c}$

4

$5{ }^{a}$ Research Reactor Institute, Kyoto University, 2-1010 Asashiro Nishi, Kumatori,

6 Sennan Osaka 590-0494, Japan

$7{ }^{\mathrm{b}}$ Department of Earth and Planetary Sciences, Washington University in St. Louis,

8 Campus Box 1169, 1 Brookings Drive, Saint Louis, MO 63130-4862, USA

9 ' Laboratoire de Sciences de la Terre, UMR 5570 CNRS, Ecole Normale Supérieure de

10 Lyon, 46, Allee d'Italie, 69364 Lyon Cedex 7, France

*Author to whom correspondence should be addressed

14 tosiyuki@rri.kyoto-u.ac.jp

15 TEL: +81-724-51-2469, FAX: +81-724-51-2634

16

17 Keywords: Nuclear field shift; Mass-independent; Isotope fractionation; Chemical exchange 18 
Abstract

Mass-independent isotope fractionations found in laboratory-scale chemical exchange experiments are reviewed. The classic theory of stable isotope fractionation in chemical exchange reactions has been established by Bigeleisen, Mayer, and Urey in 1947. In 1996, the conventional mass-dependent theory was expanded by Bigeleisen to include a mass-independent term named the nuclear field shift effect. The nuclear field shift is an isotope shift in orbital electrons, which results from the isotopic difference in nuclear size and shape. Since the revised theory was proposed, the mass-independent isotope fractionation of various elements, (e.g., Ti, Cr, Zn, Sr, Mo, Ru, Cd, Sn, Te, Ba, Nd, Sm, $\mathrm{Gd}, \mathrm{Yb}$, and $\mathrm{U}$ ), found in chemical exchange systems has been successfully explained as the nuclear field shift effect. In this review article, from both theoretical and experimental viewpoints, origins of mass-independent isotope effects are discussed. 


\section{Introduction}

This article presents an overview of the mass-independent isotope fractionation found in laboratory scale chemical exchange experiments, whose origin is considered to be the nuclear field shift effect. The fundamental theory of the chemical isotope effect was established by Urey (1947) and Bigeleisen and Mayer (1947). From the theory, at a constant temperature, the isotope enrichment factor is proportional to the isotopic mass difference $\delta m$ and inversely proportional to the product of masses $m$ and $m$ ' of two isotopes. As long as four decades after the formulation of the mass-dependent theory, a failure of the isotope effect in chemical exchange equilibria to follow the theory has not been reported.

Mass-independent isotope fractionations were first observed for $\mathrm{O}$ and $\mathrm{S}$ (see a review by Thiemens, 2006). The difference in the symmetry and the densities of states of the activated isotopomers is a possible origin for these mass-independent isotope fractionations (Hathorn and Marcus, 1999). Alternative interpretations have been discussed in review articles (Weston, 1999; Thiemens, 2006). For heavy elements, an anomalous isotope effect in chemical exchange was found in an isotope enrichment of ${ }^{235} \mathrm{U}$ in a redox reaction (Fujii et al., 1989a,b). Isotope enrichment factors for even atomic mass isotopes, ${ }^{234} \mathrm{U},{ }^{236} \mathrm{U}$, and ${ }^{238} \mathrm{U}$, showed a mass-dependent line, while that of ${ }^{235} \mathrm{U}$ deviated from that line. After that observation, the anomalous isotope enrichment of odd atomic mass isotopes has been examined. In cation exchange chromatography, a similar property has been found in ${ }^{157} \mathrm{Gd}$ enrichment (Chen et al., 1992), while fractionations of Ca (Oi et al., 1993), Sr (Oi et al., 1992), and Ba (Kondoh et al., 1996) isotopes showed the conventional mass-dependent trends. Nishizawa et al. (1993, 1994) have found different fractionation properties between odd and even atomic mass 
isotopes of $\mathrm{Zn}$ (1993), Sr (1994), and Ba (1994) in a liquid-liquid extraction system with a macrocyclic polyether. The effect was named "odd/even isotope effect" (Nishizawa et al., 1994), but at that time, the origin of the odd/even isotope effect was not clear.

A further investigation on the odd/even isotope effect has been carried out for Sr isotopes (Nishizawa et al., 1995). In the study, a similarity between the odd/even isotope effect and the odd-even staggering found in atomic spectra was observed. In atomic spectra, lines of the odd isotopes do not lie midway between the adjacent even isotopes, but are shifted towards the isotope of lower atomic mass number. This effect, which is known as the odd-even staggering (Stacy, 1966; Kurn, 1969; Heilig and nuclear charge distribution is affected by the number of neutrons in the nucleus. The nuclear charge distribution gives an electric field, and its isotopic difference shifts the atomic energy levels (details will be explained in section, 4.1), also displacing the electronic molecular states. The nuclear field shift is not mass-dependent but is strongly 
or

$$
\mathrm{A}^{\prime} \mathrm{X}+\mathrm{Y} \rightleftarrows \mathrm{A}^{\prime} \mathrm{Y}+\mathrm{X}, \quad \Delta G_{2}{ }^{\circ}
$$

99

\section{Chemical exchange reaction}

$$
\mathrm{AX}+\mathrm{Y} \rightleftarrows \mathrm{AY}+\mathrm{X}, \quad \Delta G_{1}{ }^{\circ}
$$
and $\mathrm{AY}$,

100 ligands. $\Delta G_{1}{ }^{\circ}$ and $\Delta G_{2}{ }^{\circ}$ are the standard free energies of the reactions. The difference

related to neutron configuration of a nuclear structure. The nuclear field shift effect is therefore a mass-independent isotope effect. The new theory gave a sufficient explanation of the anomalous isotope enrichment of U. Nomura et al. (1996) have independently come to the same conclusion. At the current stage, the Bigeleisen 1996 theory is the most reliable theory for studying the mass-independent isotope fractionation found in chemical exchange reactions.

The theory of chemical isotope effect has been derived for equilibrium reactions based upon the calculation of the isotopic reduced partition function (Urey, 1947; Bigeleisen and Mayer, 1947). The isotopic reduced partition function based on differences in vibrational frequencies of isotopically substituted molecules is an estimate of isotopic partitioning between a separated atom and the molecule.

Chemical exchange is known as a potential method for separating isotopes (London, 1961). A chemical exchange reaction can be represented as two half-reactions,

9 where $\mathrm{A}$ and $\mathrm{A}^{\prime}$ are the heavy and light isotopes of the element $\mathrm{A}$, and $\mathrm{X}$ and $\mathrm{Y}$ represent between reactions 1 and 2 corresponds to an isotopic exchange reaction between $\mathrm{AX}$

$$
\mathrm{A}^{\prime} \mathrm{Y}+\mathrm{AX} \rightleftarrows \mathrm{A}^{\prime} \mathrm{X}+\mathrm{AY}, \quad \Delta G^{\circ}=\Delta G_{1}{ }^{\circ}-\Delta G_{2}{ }^{\circ}
$$


For example, isotopes of light elements, C (Hutchison et al., 1940), N (Urey et al., 1937), and S (Stewart and Cohen, 1940), were successfully separated by chemical exchange in Urey's pioneering work. Even for heavy elements like U, isotope enrichment by chemical exchange is feasible (see a review by Bigeleisen, 1992).

The equilibrium constants of reactions 1 and 2 are,

$$
K_{1}=\frac{\gamma_{\mathrm{AY}}[\mathrm{AY}] \gamma_{\mathrm{X}}[\mathrm{X}]}{\gamma_{\mathrm{AX}}[\mathrm{AX}] \gamma_{\mathrm{Y}}[\mathrm{Y}]}
$$

and,

$$
K_{2}=\frac{\gamma_{\mathrm{A}^{\prime} \mathrm{Y}}\left[\mathrm{A}^{\prime} \mathrm{Y}\right] \gamma_{\mathrm{X}}[\mathrm{X}]}{\gamma_{\mathrm{A}^{\prime} \mathrm{X}}\left[\mathrm{A}^{\prime} \mathrm{X}\right] \gamma_{\mathrm{Y}}[\mathrm{Y}]}
$$

where $\gamma$ means the activity coefficient. $K_{1} / K_{2}$ can be calculated as,

$$
\frac{K_{1}}{K_{2}}=\frac{\left(\gamma_{\mathrm{AY}}[\mathrm{AY}]\right) /\left(\gamma_{\mathrm{A}^{\prime} \mathrm{Y}}\left[\mathrm{A}^{\prime} \mathrm{Y}\right]\right)}{\left(\gamma_{\mathrm{AX}}[\mathrm{AX}]\right) /\left(\gamma_{\mathrm{A}^{\prime} \mathrm{X}}\left[\mathrm{A}^{\prime} \mathrm{X}\right]\right)}
$$

This is identical with the equilibrium constant $K$ of the isotopic exchange reaction 3 . From the general thermodynamic relation $\Delta G^{\circ}=-R T \ln K$, a relation $\Delta G_{1}{ }^{\circ}-\Delta G_{2}{ }^{\circ}=-$ $R T \ln K_{1}-\left(-R T \ln K_{2}\right)=-R T \ln \left(K_{1} / K_{2}\right)$ can be obtained. Hence, the relation $K=K_{1} /$ $K_{2}$ is thermochemically consistent.

Under the equilibrium of reaction 3, if the chemical species $\mathrm{AX}$ and $\mathrm{A}^{\prime} \mathrm{X}$ are separated from $\mathrm{AY}$ and $\mathrm{A}^{\prime} \mathrm{Y}$, isotope fractionation can be evaluated. In the case, the equilibrium isotope separation factor $\alpha$ is defined as,

$$
\alpha=\frac{\left([\mathrm{A}] /\left[\mathrm{A}^{\prime}\right]\right)_{\mathrm{Y}}}{\left([\mathrm{A}] /\left[\mathrm{A}^{\prime}\right]\right)_{\mathrm{X}}}
$$

where $\left([\mathrm{A}] /\left[\mathrm{A}^{\prime}\right]\right)_{\mathrm{X}}$ means the isotopic composition corresponding to $\mathrm{AX}$ and $\mathrm{A}^{\prime} \mathrm{X}$, while $\left([\mathrm{A}] /\left[\mathrm{A}^{\prime}\right]\right)_{\mathrm{Y}}$ corresponds to $\mathrm{AY}$ and $\mathrm{A}^{\prime} \mathrm{Y} .\left([\mathrm{A}] /\left[\mathrm{A}^{\prime}\right]\right)_{\mathrm{X}}$ and $\left([\mathrm{A}] /\left[\mathrm{A}^{\prime}\right]\right)_{\mathrm{Y}}$ may be the isotopic 
compositions of two different equilibrated phases, e.g., an aqueous phase and an organic phase in solvent extraction, a resin phase and a liquid phase in chromatography, and so on. Under an assumption that the activity coefficient is isotope-independent, that is, $\gamma_{\mathrm{AX}}$ $=\gamma_{\mathrm{A}^{\prime} \mathrm{X}}$ and $\gamma_{\mathrm{AY}}=\gamma_{\mathrm{A}^{\prime} \mathrm{Y}}$ (see Eq. 6), the isotope separation factor $\alpha$ is equal to the equilibrium constant $K$ of reaction 3 .

The isotope enrichment factor $\varepsilon$ is defined as,

$$
\varepsilon=\alpha-1
$$

Considering the magnitude of chemical isotope fractionation, an approximation, $\alpha-1 \approx$ $\ln \alpha($ or $\varepsilon \approx \ln (1+\varepsilon)$ ), can be applied. Here $\alpha$ and $\varepsilon$ have been defined for a single stage reaction. Since chromatography is a multistage process, $\alpha$ and $\varepsilon$ values are usually extracted from measurements by using equations proposed by Spedding (1955), Glueckauf (1955), or Kakihana and Kanzaki (1969). It should be noted that $\varepsilon$ here is different from that usually used in geochemistry (the use of $\varepsilon$ to indicate a fractionation factor is not uncommon in environmental geochemistry). $\varepsilon$ in Eq. 8 is as defined and used for engineered isotope enrichment. One can see that $10^{3} \varepsilon$ is similar to the delta unit used in geochemistry.

\section{Bigeleisen-Mayer's (1947) theory of mass-dependent fractionation}

Isotope effects in chemical exchange (reaction 3) caused by intramolecular vibration has been clearly explained by Bigeleisen and Mayer (1947). A review prepared by Ishida (2002) is helpful for understanding it. The equilibrium constant $K$ in the isotope exchange reaction 3 is, 


$$
K=\frac{\left(\frac{s}{s^{\prime}} f\right)_{\mathrm{Y}}}{\left(\frac{s}{s^{\prime}} f\right)_{\mathrm{X}}}
$$

144

145

150

151

where $s$ is the number of identical configurations obtained by fundamental geometric operations on each molecule such as symmetry or rotation (e.g., $s=1$ for $\mathrm{HCl}, 2$ for $\mathrm{O}_{2}$, 12 for $\left.\mathrm{CH}_{4}\right)$, and $\mathrm{X}$ and $\mathrm{Y}$ represent ligands. The number $\left(s / s^{\prime}\right) f$ is called the "reduced partition function ratio." $\left(s / s^{\prime}\right) f$ is generally expressed as follows via the Bigeleisen-Mayer second-order approximation,

$$
\frac{s}{s^{\prime}} f=1+\frac{1}{24}\left(\frac{\hbar}{k T}\right)^{2} \frac{\delta m}{m m^{\prime}}\left\langle\nabla^{2} U\right\rangle
$$

where $\hbar, k$, and $T$ are the Plank constant, the Boltzmann constant, and temperature, respectively. $m$ and $m^{\prime}$ are masses of two isotopes $\mathrm{A}$ and $\mathrm{A}^{\prime} . \delta m / \mathrm{mm}^{\prime}$ represents $\left(1 / \mathrm{m}^{\prime}-\right.$ $1 / m) .\left\langle\nabla^{2} U\right\rangle$ is the averaged Laplacian of the intramolecular potential. This approximation is only valid at relatively high temperature (Bigeleisen, 1947; Ishida, 2002). Consider a molecule, in which the central atom of mass $m$ or $m$ ' is symmetrically surrounded by $n$ identical atoms (ligands) of mass $M$. Equation 10 can be simply rewritten as,

$$
\frac{s}{s^{\prime}} f=1+\frac{1}{24}\left(\frac{\hbar}{k T}\right)^{2} \frac{\delta m}{m m^{\prime}} M v^{2} n
$$

where $v$ is the vibrational frequency (totally symmetric frequency) of the molecule. Since the second term of right hand of Eq. 11 is much smaller than unity, similar approximation like $\ln (1+\varepsilon) \approx \varepsilon$ can be applied. From Eqs. 8, 9, and 11, and the relation $\alpha \approx K$, the isotope enrichment factor can be written as, 


$$
\begin{aligned}
& \varepsilon=\alpha-1 \approx \ln \alpha \approx \ln K \\
& =\ln \left(\frac{s}{s^{\prime}} f\right)_{Y}-\ln \left(\frac{s}{s^{\prime}} f\right)_{X} \\
& \approx \frac{1}{24}\left(\frac{\hbar}{k T}\right)^{2} \frac{\delta m}{m m^{\prime}}\left(M_{Y} v_{Y}{ }^{2} n_{Y}-M_{X} v_{X}{ }^{2} n_{X}\right)
\end{aligned}
$$

$163 M, v$, and $n$ are known values, if the related chemical species are clearly identified.

164 Therefore, $\varepsilon$ is a function of $\delta m / \mathrm{mm}^{\prime}$ and $T^{2}$.

The Bigeleisen-Mayer theory may be understandable by using the vibrational potential curve of a diatomic molecule (Fig. 1). The theory contains three assumptions which must be accounted for:

168 (1) Although the Morse potential energy curve is more realistic (see Fig. 1), the vibrational energy levels are usually approximated by the energy levels

$170 \quad E_{n}=\left(n+\frac{1}{2}\right) h v(n=0,1, \ldots)$ of a harmonic oscillator, in which $v=\frac{1}{2 \pi} \sqrt{\frac{\kappa}{\mu}}$, with $\kappa$ being the force constant and $\mu$ the reduced mass of the molecule.

(2) Because it is acting between the electrons orbiting each atom of the molecule, the force constant $\kappa$ of isotopologues is isotope-independent (for the definition of "isotopolog", see (Minkin, 1999). Hence, the harmonic potential curve is the same for all isotopologues, and only the permissible energy levels, including the zero point energy $(n=0)$ are isotope-dependent.

(3) The minimum value of the potential energy of isotopologues is isotope-independent. It is convenient to assume $\delta E^{\circ}$ in Fig. 1 is zero.

179 These assumptions lead to correction terms. Especially, assumption (3) leads to a major 180 correction. The assumption (3) means that no isotope fractionation occurs via the 
electronic partition function $Q_{\mathrm{e}}$, but $\delta E^{\circ}$ (Fig. 1) has a significant value which changes Q. A correction term for the assumption (3) is the origin of mass-independent isotope effect named the nuclear field shift effect.

\section{Bigeleisen's (1996) theory}

Bigeleisen (1996a) has improved the Bigeleisen-Mayer equation by adding correction terms. The correction terms mainly result from isotope shifts in electronic molecular energy states. Knowledge of isotope shifts in atomic and molecular spectra is helpful to understand the theory.

\subsection{Isotope shifts in atomic spectra}

Evidence of energy quantization comes from the observation that the frequencies of radiation absorbed or emitted by atoms and molecules depend on the isotope. The differences resulting from the substitution of an isotope by another are called "isotope shifts". Isotope shifts are best known for atomic spectra, and therefore will be the main focus of this section. A number of detailed reviews (Breit, 1958, Stacy, 1966; Kurn, 1969; Heilig and Steudel, 1978, Aufmuth et al., 1987) and books (King, 1984; Fricke and Heilig, 2004) covering various aspects of isotope shifts have appeared over the past fifty years. In this section, only the basic principles will be reviewed.

Each atomic energy level is characterized by an eigenfunction of the Schrödinger equation. The associated eigenvalues define the angular momentum and the energy of this level. Mass differences between isotopes lead to shifts in the atomic energy level, because the orbital angular momentum remains the same. This isotope shift is called the mass shift. Since the nucleus is much heavier than an electron, it 
moves relatively slowly and is usually approximately treated as stationary: this is the Born-Oppenheimer approximation. For light nuclides, however, the movement of the nucleus can no longer be neglected and its movement around the center of the gravity of the nucleus-electrons ensemble creates a kinetic momentum. Each orbital electron receives an excess kinetic momentum via the movement of the nucleus. The kinetic momentum is a function of mass. The isotopic difference in the mass of the nucleus results in the mass shift in atomic energy levels. One can regard the mass shift as a correction to the Born-Oppenheimer approximation. The mass shift is the sum of the normal mass shift and the specific mass shift. The normal mass shift can be calculated under the assumption that the electron wave functions are uncorrelated. The specific mass shift considers the correlation between the electron wave functions. The mass shift is proportional to the isotopic mass difference $\delta m$ and inversely proportional to the product of masses $m$ and $m^{\prime}$ of two isotopes $\left(\propto \delta m / m^{\prime}\right)$.

Another isotope shift accounts for the deviation of nuclear charge distribution from a point-charge distribution. It is called the field shift and is important because the atomic energy depends upon the size and shape of the electric charge distribution of the nucleus. In general, the field shift is smaller than the mass shift for light elements, but for heavy elements, it is relatively large compared to the mass shift (see Fig. 1 reported by Stern and Snavely, 1976). As mentioned above, the nuclear charge distribution gives rise to an electric field, and differences in nuclear charge radius associated with the number of neutrons shift the atomic energy levels. Consider the electrostatic interaction between the orbital electrons and the nucleus. Electrostatic potentials of nuclei are shown in Fig. 2. Away from the nuclear region, the electric field of the nucleus can be represented as a Coulomb potential identical for all isotopes. Within the nuclear region, 
229

230

234

235

it is isotopically different. For example, since the wave functions of the $s$-electrons do not go to zero next to a finite size nucleus, the effect depends on the isotope. A larger nuclear charge distribution gives a smaller binding potential than a point-charge distribution. The field shift in an atomic energy level $\left(\delta E_{\mathrm{fs}}\right)$ can be shown to be (King, 1984),

$$
\delta E_{\mathrm{fs}}=\pi|\psi(0)|^{2} \frac{a_{0}^{3}}{Z} f(Z) \delta<r^{2}>
$$

where $|\Psi(0)|^{2}$ is the electron density at the nucleus. $a_{0}$ means the Bohr radius. $f(Z)$ is a known function for each element of atomic number $Z . \delta<r^{2}>$ means the isotopic difference in the mean-square charge radius $\left(=\left\langle r^{2}\right\rangle_{A}-\left\langle r^{2}\right\rangle_{A^{\prime}}\right)$. From Eq. 13, it is clear that the field shift is proportional to $\delta<r^{2}>$. Due to the systematics of neutron configuration, $<r^{2}>$ shows odd-even staggering (a "saw-tooth" figure), and the nucleus is particularly compact with magic number neutrons $(20,28,50,82$, and 126) (see Fig. 3 in a review by Aufmuth et al., 1987).

It is known that a change in the shape of a nucleus can also give rise to a field shift, even if the actual volume of the nuclear charge distribution does not change. $\delta<r^{2}>$ obtained from isotope shifts includes information of both the nuclear size and the nuclear shape. For a non-spherical charge distribution, the second-degree deformation is accounted for by a quadrupole term with axial symmetry, and the mean-square charge radius becomes (Heilig and Steudel, 1978),

$$
<r^{2}>\approx \frac{3}{5} r_{0}\left(1+\frac{5}{4 \pi}<\beta^{2}>\right)
$$

where $r_{0}$ is the equilibrium charge radius of the drop (liquid-drop model) and $<\beta^{2}>$ the 
mean-square quadrupole deformation parameter. This parameter can be obtained from

250 the reduced nuclear transition probability of nuclear $0^{+} \rightarrow 2^{+}$transition, $B\left(E 2,0^{+} \rightarrow 2^{+}\right)$.

$$
<\beta^{2}>=B\left(E 2,0^{+} \rightarrow 2^{+}\right)\left(\frac{3 Z r^{2}}{4 \pi}\right)^{-2}
$$

with $r=1.2 A^{1 / 3} \mathrm{fm}$, where $Z$ and $A$ are the element number and the mass number, respectively. For the neutron-rich even isotopes of $\mathrm{Nd}, \mathrm{Sm}$, and $\mathrm{Gd}$, the $<\beta^{2}>$ values show drastic changes with the atomic mass number, which suggests that, in these cases, the changes in the nuclear shape have more effect on $\left\langle r^{2}\right\rangle$ than change in the nuclear size (King, 1984) (for example, ${ }^{150} \mathrm{Sm},{ }^{152} \mathrm{Sm}$, and ${ }^{154} \mathrm{Sm}$ ).

The total angular momentum must be conserved during a reaction. Protons, neutrons, and electrons are fermions with spins of $\pm \frac{1}{2}$. For nuclides with even numbers of protons and neutrons, i.e., with integer nuclear spin, there is no spin effect. In other cases, and in particular for nuclides of odd masses, the spin of unpaired protons and neutrons interact with the orbital momentum of the electrons (Herzberg, 1944). The total angular momentum $F$ is the resultant of the coupling of the nuclear spin $I$ with the total angular momentum of electrons $J$. The corresponding quantum number $F$ can take values,

$$
F=J+I, J+I-1, J+I-2, \cdots,|J-I|
$$

This gives $2 J+1$ or $2 I+1$ different values depending on whether $(J<I)$ or $(J>I)$. Consequently, a small energy difference between states with different $F$ exists. Since the magnetic moment of the nucleus is smaller (by approximately a factor of 2,000) than that of the electron, the energy differences are very small. The spectrum shift due to the coupling between $J$ and $I$ is referred to as the "hyperfine structure" or "hyperfine 
splitting."

In a magnetic field, a space quantization of $F$ takes place. The quantum number $M_{F}$ of the component of the angular momentum in the field direction can take,

$$
M_{F}=F, F-1, F-2, \cdots,-F
$$

The $2 F+1$ values of $M_{F}$ correspond to states of different energies in a magnetic field. In the absence of the magnetic field, these energy levels are degenerated to be unity. Under a strong magnetic field, these levels are split. This effect is called the Zeeman effect (for example, Fig. VI, 12 in the book by Kuhn, 1969). In general, a field of 20,000 G is needed to produce a splitting of about $1 \mathrm{~cm}^{-1}$ (Atkins, 1998).

A space quantization of total angular momentum $F$ also takes place in electric fields and the $2 F+1$ levels are also split. All splitting levels are doublets $\left( \pm M_{F}\right)$ except for $M_{F}=0$ (singlet). This effect is called the Stark effect (Herzberg, 1944; Atkins, 1998).

Except for strong electromagnetic fields, the hyperfine splitting shifts due to the $I-J$ coupling can be predicted. In order to calculate the hyperfine structure, the centroid of the energy levels must be calculated. If the energy reference level is set to be zero, the condition is,

$$
\sum N_{\mathrm{i}} \Delta E_{\mathrm{i}}=0
$$

where $N_{\mathrm{i}}$ is the occupation number of $i$ th hyperfine splitting level and $\Delta E_{\mathrm{i}}$ is the energy difference from the energy gravity. The value of $N_{\mathrm{i}}$ for each hyperfine splitting level can then be calculated as,

$$
N_{\mathrm{i}}=\frac{2 F_{i}+1}{\sum(2 F+1)}
$$


Bigeleisen (1996a) expanded his original mass-dependent theory of reduced partition functions (Bigeleisen and Mayer, 1947), and therefore of isotope separation factor $\alpha$, by adding correction terms. The isotope enrichment factor $\varepsilon(\approx \ln \alpha)$ is,

$$
\ln \alpha=\ln \alpha_{0}+\ln K_{\mathrm{anh}}+\ln K_{\mathrm{BOELE}}+\ln K_{\mathrm{hf}}+\ln K_{\mathrm{fs}}
$$

where $\ln \alpha_{0}$ is the Bigeleisen-Mayer equation (Eq. 12). The correction terms are

- the anharmonic vibration correction $\left(K_{\text {anh }}\right)$

- the correction to the Born-Oppenheimer approximation $\left(K_{\mathrm{BOELE}}\right)$

- the nuclear spin effect $\left(K_{\mathrm{hf}}\right)$, and

- the nuclear field shift effect $\left(K_{\mathrm{fs}}\right)$.

298 The anharmonic correction is in the order of $1 \%$ of $\ln \alpha_{0}$ even for ${ }^{2} \mathrm{H} /{ }^{1} \mathrm{H}$ exchange reactions (Bigeleisen, 1996a). Even if the potential energy curve (Fig. 1) is treated as the Morse type or the typical parabola type, the difference is insignificant.

All the correction terms $K_{\mathrm{BOELE}}, K_{\mathrm{fs}}$, and $K_{\mathrm{hf}}$, originate from the isotopic displacement of the molecular energy state. They are attributable to the mass shift, the field shift, and the hyperfine splitting shift, respectively. In other words, they are attributable to the isotopic differences in the nuclear mass, the nuclear size and shape, and the nuclear spin, respectively. In Fig. 1, the isotope separation factor due to $\delta E^{\circ}$ functions,

$$
\alpha\left(\delta E^{\circ}\right)=\frac{\left(Q_{e} / Q_{e}{ }^{\prime}\right)_{Y}}{\left(Q_{e} / Q_{e}{ }^{\prime}\right)_{X}}=\frac{e^{-\delta E_{Y}^{\circ} / k T}}{e^{-\delta E_{X}^{\circ} / k T}}
$$


The isotope enrichment factor is,

$$
\varepsilon\left(\delta E^{\circ}\right) \approx \ln \alpha\left(\delta E^{\circ}\right)=\frac{1}{k T}\left(\delta E_{X}^{\circ}-\delta E_{Y}^{\circ}\right)
$$

309 On a spectroscopic basis, $\delta E^{\circ}$ can be replaced by $h v$, where $v$ stands for the frequency 310 of isotope shift in wavenumbers. The magnitude of isotope fractionation may be predicted by substituting the value of optical isotope shifts into Eq. 22, though it is based on an assumption that the minimums of potential curves have similar isotopic displacements.

The correction to the Born-Oppenheimer approximation has been investigated by Kleinman and Wolfsberg (1973 and 1974a,b). The $K_{\text {BOELE }}$ value has been estimated for a reaction involving uranium isotopologues, in which it was concluded that the correction due to this term was negligible (Bigeleisen, 1996a). Considering the predominance of mass shift in isotope shifts, $K_{\mathrm{BOELE}}$ for lighter elements should be more important. The effect is however mass-dependent. The correction term $K_{\mathrm{hf}}$ for uranium has been calculated to be negligibly small (Bigeleisen, 1996a).

\subsection{Comments on the nuclear spin effect}

Let us now re-assess the reasons why Bigeleisen (1996a) concluded the nuclear spin effect be negligible. The data used are the hyperfine splitting shifts obtained from the electron magnetic resonance analysis of $\mathrm{a}^{235} \mathrm{U}(\mathrm{III})$ complex and are shown in Fig. 3. The $\Delta E_{\mathrm{i}}$ values were equated to the energy differences of hyperfine splitting levels of ${ }^{235} \mathrm{U}$ with respect to the ground energy level of the ${ }^{238} \mathrm{U}(\mathrm{III})$ complex. As discussed in the previous section, the Stark effect must be considered for the case of a strong electromagnetic field. In this case, the occupation number of each state is not the usual 
case of Eq. 19, but,

$$
N_{i}=\frac{g_{i}}{\sum g}
$$

331 where $g_{\mathrm{i}}$ is the degeneracy ( 2 for doublet and 1 for singlet) of the $i$ th hyperfine splitting

332 level. If the mean weighted value of the hyperfine splitting levels is defined as the 333 reference level, the following relation is obtained,

$$
\Sigma g_{\mathrm{i}}\left(\Delta E_{\mathrm{i}}-\delta \Delta E\right)=0
$$

334 where $\delta \Delta E$ means the difference of the energy gravity from the ${ }^{238} \mathrm{U}$ ground energy state.

335 This equation is similar to Eq. 18. Since $\Delta E_{\mathrm{i}}$ here is the energy difference from the ${ }^{238} \mathrm{U}$ 336 ground energy state, $\delta \Delta E$ must be subtracted from $\Delta E_{\mathrm{i}}$. The literature value of $\delta \Delta E$ 337 (Table 2, Bigeleisen, 1996a) is only of $0.003 \mathrm{~cm}^{-1}$, i.e., about 10 times smaller than the 338 largest $\Delta E_{\mathrm{i}}$ (see Table 2, Bigeleisen, 1996a)). The partition function of the nuclear spin 339 effect was defined by Bigeleisen (1996a) as,

$$
Q_{\mathrm{ns}} g=\sum g_{i} e^{-\frac{\Delta E_{i}}{k T}}
$$

340 Since the $\exp \left(-\Delta E_{\mathrm{i}} / k T\right)$ value is very close to unity, the following approximation $341 \exp \left(-\Delta E_{\mathrm{i}} / k T\right) \approx 1-\Delta E_{\mathrm{i}} / k T$ holds, and so Eq. 25 may then be rewritten as,

$$
Q_{\mathrm{ns}} g \approx \sum g_{i}\left(1-\frac{\Delta E_{i}}{k T}\right)
$$

342 The $\Delta E_{\mathrm{i}} / k T$ value is much smaller than the magnitude of $g$. This equation suggests that the $\Delta E_{\mathrm{i}} / k T$ term, which accounts for the nuclear spin effect, only changes $g$ by a factor very close to unity. Equation 26 can now be rewritten,

$$
Q_{\mathrm{ns}} g \approx \sum g_{i}-\frac{1}{k T} \sum g_{i} \Delta E_{i}
$$


In Eq. 24, if $\delta \Delta E<<\Delta E_{\mathrm{i}}$, the approximation $\Sigma g_{\mathrm{i}} \Delta E_{\mathrm{i}} \approx 0$ holds and changes Eq. 27 into

$346 Q_{\mathrm{ns}} g \approx \sum g_{\mathrm{i}}$, which indicates that, within the approximation of this calculation, the nuclear spin effect can be neglected.

According to the definition by Bigeleisen (1996a), the magnitude of the nuclear spin effect $\left(\ln K_{\mathrm{hf}}\right)$ should decrease with decreasing $\delta \Delta E$. A very small nuclear spin effect of ${ }^{235} U$ therefore only reflects that the value of $\delta \Delta E$ used was very small. The magnitude of $\delta \Delta E$ is therefore much more important than the number and spacing of the hyperfine splitting levels. $\delta \Delta E$ refers to the same quantity as $\delta E^{\circ}$ in both Eqs. 21 and 22 to be the nuclear field shift. The final equation in Bigeleisen's (1996a) theory is hence obtained by adding Eq. 22 (corresponding to the field shift) to Eq. 12 .

$$
\ln \alpha=\frac{h}{k T} v_{\mathrm{fs}} a+\frac{1}{24}\left(\frac{\hbar}{k T}\right)^{2} \frac{\delta m}{m m^{\prime}} b
$$

where $a$ is the field shift scaling factor and $b$ is the scaling factor for the conventional mass effect (strictly, the mean Laplacian of the intramolecular potential). The first term is the mass-independent term named the nuclear field shift effect. (see section, 3), the consequences of assumptions (1) (harmonicity) and (3) (minimum 364 of potential energy) were clarified as the correction terms in the Bigeleisen's (1996) theory. For the assumption (2), later, it has been identified as a second-order correction 
to the nuclear field shift (Bigeleisen, 1998).

\subsection{Second-order correction to the nuclear field shift effect.}

A breakdown of the assumption (2) due to wavefunctions of bonding electrons being disturbed by the nuclear charge distribution has been pointed out by Nishizawa et al. (1995). This idea has come from the studies on field shifts in molecular spectra (Tiemann et al., 1982; Schlembach and Tiemann, 1982). In the Bigeleisen 1996 theory, the nuclear field shift effect in the electronic partition function has been focused, but not in the vibrational partition function.

The vibrational frequency of the molecule can be simply written,

$$
v=\frac{1}{2 \pi} \sqrt{\frac{\kappa}{\mu}}
$$

where $\kappa$ and $\mu$ are the force constant and the reduced mass, respectively. In the classic theory, only the isotopic difference in $\mu$ has been treated based on the assumption that $\kappa$ is isotope-independent (see Assumption (2) in Chapter 3). Due to the field shift, $\kappa$ should have an isotopic difference $\delta \kappa$, which is proportional to $\delta<r^{2}>$. This has been theoretically and experimentally proven by Schlembach and Tiemann (1982). If $\delta \kappa$ is introduced, the logarithm of Eq. 11 can be rewritten as (Fujii et al, 2000, 2001a),

$$
\ln \left(\frac{s}{s^{\prime}}\right) f=\frac{1}{24}\left(\frac{\hbar}{k T}\right)^{2} \frac{\delta m}{m m^{\prime}} M v^{2} n+\frac{1}{24}\left(\frac{\hbar}{k T}\right)^{2}\left(\frac{1}{m}+\frac{1}{M}\right) \delta \kappa n
$$

The question is whether the magnitude of $\delta \kappa$ is significant or not. Bigeleisen (1998) has estimated the nuclear field shift effect in the vibrational partition function for a $\mathrm{Pb}$ isotopologue. The magnitude was $0.3 \%$ of the $\ln \left(s / s^{\prime}\right) f$, and hence, the effect has been concluded to be only a second-order correction to the Bigeleisen-Mayer equation. 
First-principles calculations, which allow for the isotopic difference in the

387

\subsection{Experimental and theoretical approaches}

There are two effective ways to examine experimental results by employing Eq. 28 . The first way is graphically shown in Fig. 4. This evaluation method needs isotopes whose $<r^{2}>$ 's have mass-independent characteristics. Prominent mass-independent properties are shown in the plots of $\delta<r^{2}>v s \delta m / m m$ ' for Ca, Cr, Ba, and Ce (Figs. 5 b, d, m, and n), whereas the relation for some elements (for example, Fe, Fig. 5e) shows a mass-dependent trend.

At a constant temperature, Eq. 28 can be simplified as,

$$
\ln \alpha=\delta<r^{2}>A+\frac{\delta m}{m m^{\prime}} B
$$

where $A$ and $B$ are scaling factors for the nuclear field shift effect and the mass effect, respectively. The isotope enrichment factors obtained experimentally are plotted as a function of $\delta m / \mathrm{mm}^{\prime}$. If the plots are linear, the nuclear field shift cannot be separated from other mass-dependent fractionation effects, which often reflects that $\delta<r^{2}>$ varies linearly with $\delta \mathrm{m} / \mathrm{mm}^{\prime}$ (see Fig. 5e). Deviation from linearity indicates, however, a mass-independent component which is most easily accounted for by the nuclear field shift effect. If the element has three or more isotopes, the scaling factors $A$ and $B$ can be 
analyzed by fitting Eq. 31 to the experimental results. Because Eq. 31 can be arbitrarily fitted to any three isotope systems, unambiguous demonstration of a nuclear field shift effect requires four or more isotopes (at least three even atomic mass isotopes and one odd atomic mass isotope). Deviation of experimental values from the predicted values at odd atomic mass isotopes may signal a nuclear spin effect. The case for nuclear field shift isotope effects can be strengthened if the fit succeeds in reproducing two characteristics that coexist in some elements with a number of neutrons or protons close to those of a full-shell (magic numbers), the odd-even staggering and the non-linear variation of the $\delta<r^{2}>$ of even isotopes with respect to $\delta m / m m$. Elements that best fulfill these conditions may be $\mathrm{Ca}, \mathrm{Cr}, \mathrm{Ba}$, and so on, which have isotopes with magic number of neutron.

After separating the mass-dependent and the mass-independent components, the validity of the magnitude of each component can be checked. The isotope enrichment factor of the conventional isotope effect can be calculated by employing the Bigeleisen-Mayer equation (1947). The interatomic vibrational frequencies required for the calculation can be obtained from spectrophotometry (Raman and IR) or from electronic structure calculations. $K_{\mathrm{BOELE}}$ for some isotopologues can be estimated from literature data (Kleinman and Wolfsberg, 1973 and 1974a,b). A simplified calculation employed for uranium (Bigeleisen, 1996a), may also be effective to predict the magnitude of $K_{\text {BOELE}}$. In recent quantum chemical calculations, magnitudes of the nuclear field shift effect have been estimated for some simple molecules or ions (Schauble, 2007; Abe et al., 2008a,b).

The second way is graphically shown in Fig. 6. At various temperatures, Eq. 28 may be simplified as, 


$$
\ln \alpha=\frac{1}{T} C+\frac{1}{T^{2}} D
$$

where $C$ and $D$ are scaling factors. The $C / T$ term represents the nuclear field shift effect and the $D / T^{2}$ term the conventional mass effect. The nuclear field shift fractionation is largest at low temperatures, but tends to dominate the total fractionation at high temperature. In cases where mass-dependent and nuclear-volume fractionation act in opposite directions, there will be a maximum (or minimum) in the total fractionation factor at some finite nonzero temperature (see Fig. 6). This evaluation method has been applied by Nomura et al. (1996) and Bigeleisen (1996b). This method works for two or more isotope systems. Whether the $\left\langle r^{2}>\right.$ 's of isotopes have a mass-independent trend or not, the method can be used effectively.

However, this evaluation method involves some difficulties. From the experimental standpoint, experimental temperature range is typically very limited. The curve is thus analyzed with data within a limited $1 / T$ region. The extraction further presumes that the coordination number and/or complexation affinities of the relevant element or ion should stay the same over the sampled range of temperature. A difficulty of this evaluation method was pointed out in a study on $\mathrm{Ba}$ isotope fractionation (Shibahara et al., 2002a). An issue is that the correction term corresponding to a departure from the Born-Oppenheimer approximation, $\ln K_{\mathrm{BOELE}}$, also varies as $1 / T$. If this effect cannot be neglected, the $C / T$ term includes both mass-dependent and mass-independent components. At low temperatures and/or when the vibrational energy is high compared to the thermal energy, the isotope enrichment factor becomes proportional to $1 / T$, not to $1 / T^{2}$ (see a review by Ishida, 2002). This also interferes with the $C / T$ term. Furthermore, mass-independent fractionation seems to be more 
pronounced within a specific temperature range (Kotaka et al., 1992). One can select

455

456

457

458

459

460

461

462 the evaluation methods on the basis of the advantages and disadvantages for each of them.

\section{Kinetic effects}

Isotope fractionation may result from isotope-dependent reaction rates (e.g., formation and decomposition reactions by thermally, photochemically, or electronically activated reactions). The symmetry and the densities of states of the activated isotopologues may be different (Hathorn and Marcus, 1999). Alternative interpretations have been discussed in review articles (Weston, 1999; Thiemens, 2006).

Let us first briefly present a mechanism that involves nuclear field shift in reaction kinetics. For an isotope exchange reaction (such as the reaction 3), let us assume that there exists a transition state which controls the reaction rate and write the reaction;

$$
\mathrm{AX}+\mathrm{Y} \rightleftarrows(\mathrm{AXY})^{\ddagger} \rightarrow \mathrm{AY}+\mathrm{X}
$$

in which the suffix $\neq$ stands for the transition state. The potential curve of this reaction can be shown as Fig. 7. The isotopic ratio of reaction rate constants can be written,

$$
\frac{k}{k^{\prime}}=\frac{P}{P^{\prime}} \frac{\left(Q / Q^{\prime}\right)_{\neq}}{\left(Q / Q^{\prime}\right)_{X}}
$$

in which $P$ stands for the transmission coefficient. This is a correction coefficient in the transition state theory, which corrects the one-dimensional model. The partition function in Eq. 34 includes the electronic partition function as well as that for the equilibrium system. As shown in Fig. 7, $\delta E^{\circ}$ causes an isotope effect, in which the nuclear field shift effect exists and is predominant for heavy elements. If the magnitude of 
mass-independent isotope fractionation found in a kinetic system is comparable with that of the equilibrium system, and if its mass-independent property is similar to the $\delta<r^{2}>$ trend, then it might be affected by the nuclear field shift. If a reaction is brought to its end before equilibrium, the isotope fractionation may be affected by the kinetic isotope effect which then would also include the nuclear field shift.

The nuclear spin effect in radical reactions is known as the kinetic isotope effect (Lawler and Evans, 1971; Buchachenko, 1977) and is referred to as the "magnetic isotope effect." It reflects a magnetic field effect on the spin of excited molecules or radical pairs, e.g., photolysis of dibenzyl ketone. The rates of reaction between radical pairs are changed, not by the difference in isotopic mass, but by the hyperfine interaction between electronic and nuclear spins. The strongest magnetic isotope effects are expected for light elements like $\mathrm{C}$ and $\mathrm{O}$, but the magnitude decreases with the atomic number. This is because the spin-orbit interaction of heavier atoms, which enhances the spin conversion of radical pairs, is insensitive to external magnetic field. Nonetheless, magnetic isotope effects have also been described for heavier elements, i.e., S (Step et al., 1992), Ge (Wakasa et al., 1993, 1998), Hg (Bergquist and Blum, 2007), and U (Rykov, 1992; Buchachenko, 1995). Since radical reactions are often the hallmark of irreversible reactions, the magnetic isotope effect is different from the nuclear spin effect in equilibrium systems. If an odd/even isotope effect is found in an equilibrium system with a radical reaction, the possibility of a magnetic isotope effect nevertheless should be evaluated. The detailed mechanism of the magnetic isotope effects in radical reactions have been reviewed elsewhere (Turro, 1983; Khudyakov et al., 1993; Buchachenko, 1995, 2000, 2009; Salikhov, 1996). 


\section{Mass-independent isotope fractionations found in laboratory-scale chemical} exchange experiments

501 In this section, we summarize measured mass-independent isotope fractionations 502 element by element. We focus on the first evaluation method, described in section 4.5 and involving a plot of fractionation factors $v s \delta<r^{2}>$. For this reason, we focus on elements which have four or more isotopes. We assume that the isotope exchange reactions in ligand exchange systems and redox systems are equilibrium processes, neglecting kinetic effects (the isotopic equilibrium has been demonstrated in pioneering studies, Jepson and Cairns, 1979; Nishizawa et al., 1984). Mass-independent isotope fractionations found in laboratory-scale chemical exchange experiments are listed in Table 1. Relevant nuclear data can be found in reviews by Aufmuth et al. (1987) King (1984), and Fricke and Heilig (2004).

\subsection{Sulfur}

513 Sulfur is the lightest of the elements which have four naturally occurring isotopes $\left({ }^{32} \mathrm{~S}\right.$,

$514{ }^{33} \mathrm{~S},{ }^{34} \mathrm{~S}$, and ${ }^{36} \mathrm{~S}$ ). Mass-independent isotope fractionation of $\mathrm{S}$ has been studied in both terrestrial and extra terrestrial samples (Farquhar et al., 2000, Thiemens, 2006). Photochemical reactions as an origin of the mass-independent isotope fractionation have

517 been discussed. Mass-independent isotope fractionation of ${ }^{33} \mathrm{~S}$ has also been found 518 (Watanabe et al., 2007, 2009) in recent laboratory experiments (a kinetic redox reaction).

519 On the other hand, mass-independent isotope fractionations have not yet been found in equilibrium chemical exchange systems. Because $\mathrm{S}$ is a moderately light element, the contribution of the nuclear field shift effect may be much smaller than the mass effect

522 (Rai and Thiemens, 2007). According to quantum chemical calculations (Schauble, 
2007), the nuclear field shift effect of $S$ has been estimated to be $\sim 0.02 \%$ or an even atomic mass isotope pair, ${ }^{32} \mathrm{~S}-{ }^{36} \mathrm{~S}$. Unfortunately, $<r^{2}>$ is not yet known for ${ }^{33} \mathrm{~S}$ (Fricke and Heilig, 2004) (Fig. 5a). A possibility of the odd-even staggering in S isotope fractionation still remains, but it may be very small (Schauble, 2007).

\subsection{Calcium}

Calcium is the lightest element known to have very clear mass-independent features in its nuclear charge radii. ${ }^{40} \mathrm{Ca}$ (the most abundant) and ${ }^{48} \mathrm{Ca}$ are doubly magic, i.e., they have full shells of both neutrons and protons (Fig. 5b). Therefore, the $<r^{2}>$ 's of these two isotopes are the smallest of all stable Ca isotopes. Calcium may therefore be one of the best choices to investigate the nuclear field shift effect in very light elements.

Though there are several reports on chemical isotope fractionation of $\mathrm{Ca}$ (for example, see a review by Heumann,1985), most of the data concern two isotopes only $\left({ }^{40} \mathrm{Ca}\right.$ and $\left.{ }^{44} \mathrm{Ca}\right)$. Other early reports deal with three isotopes $\left({ }^{40} \mathrm{Ca},{ }^{44} \mathrm{Ca}\right.$, and $\left.{ }^{48} \mathrm{Ca}\right)$ (Heumann and Schiefer, 1980,1982; Jepson and Shockey, 1984), but the results show the typical mass-dependent pattern. In a three isotope system, a mass-independent isotope fractionation can be seen in some samples (e.g., sample numbers 18 to 25 , Heumann et al., 1982). Because only three isotopes were analyzed, the nuclear field shift effect cannot be unambiguously established.

Fujii et al. (1985) and Oi et al. (1993) have studied Ca isotope fractionations with five isotopes $\left({ }^{40} \mathrm{Ca},{ }^{42} \mathrm{Ca},{ }^{43} \mathrm{Ca},{ }^{44} \mathrm{Ca}\right.$, and $\left.{ }^{48} \mathrm{Ca}\right)$. Though the results were discussed in the context of mass-dependent fractionation, the isotope enrichment factors show some mass-independent isotope effects. In addition to odd-even staggering (Fig. 8), a mass-independent fractionation pattern is observed at even atomic masses. We 
reanalyzed these data by employing Eq. 31 (Fig. 8). Our calculations reproduce the observed results well. Even though the precision of the experimental data makes the discussion of mass-independent isotope fractionation tentative, the nuclear field shift effect accounts well for the apparent mass-independent component.

\subsection{Titanium}

553 Titanium has five naturally occurring isotopes $\left({ }^{46} \mathrm{Ti},{ }^{47} \mathrm{Ti},{ }^{48} \mathrm{Ti},{ }^{49} \mathrm{Ti}\right.$, and $\left.{ }^{50} \mathrm{Ti}\right)$. The $<r^{2}>$ 's of Ti show significant odd-even staggering. Ti isotopes of $\mathrm{Ti}(\mathrm{III})$ or $\mathrm{Ti}(\mathrm{IV})$ were fractionated by a liquid-liquid extraction system using a crown ether (Fujii et al., 1998a) (Fig. 9). A difference of isotope fractionation factors between Ti(III) and Ti(VI) systems may be due to the lack of $3 d$ electrons of Ti(IV), while Ti(III) possesses a single $3 d$ electron. Isotope enrichment factors show odd-even staggering (Fig 5c). The pattern of mass-independent isotope fractionation is largely consistent with the nuclear field shift. Isotope effects have also been found for odd atomic mass isotopes $\left({ }^{47} \mathrm{Ti}\right.$ and $\left.{ }^{49} \mathrm{Ti}\right)$. In addition to nuclear spin effects, the degeneracy of the hyperfine structure of the electronic partition function was considered by the authors.

\subsection{Chromium}

Chromium has four stable isotopes $\left({ }^{50} \mathrm{Cr},{ }^{52} \mathrm{Cr},{ }^{53} \mathrm{Cr}\right.$, and $\left.{ }^{54} \mathrm{Cr}\right) .{ }^{52} \mathrm{Cr}$ has a closed nuclear shell with 28 neutrons, which makes the nucleus of ${ }^{52} \mathrm{Cr}$ very compact and stable. The $<r^{2}>$ pattern for $\mathrm{Cr}$ isotopes is shown in Fig. 5d. If the mass effect is minimized by changing experimental conditions, the isotope enrichment factor should show same trend. 
ether (Kawashiro et al., 1998). Observed isotope enrichment factors follow the nuclear charge radii. Subsequent studies explored different experimental and analytical conditions (Fujii et al., 2002). MC-TIMS techniques employing a total evaporation method seem to be able to minimize instrumental bias (Fujii et al., 2006a). Fujii et al. (2007, 2008a) also used MC-ICP-MS, which has been shown yield reliable, high-precision Cr isotope compositions (Yin et al., 2007; Moynier et al., 2007a), but a reliable estimate of ${ }^{54} \mathrm{Cr}$ fractionation was not provided. Isotope enrichment factors are not strictly mass-dependent and are strongly suggestive of a substantial nuclear field shift effect. Fujii et al. (2008b) repeated extractions, and calculated the isotopic mass balance between the two phases to strengthen the evidence of mass-independent isotope effects (Fig. 10).

Isotope fractionation of $\mathrm{Cr}$ was also investigated at high temperatures (723 1023K) by contacting a molten salt $\left(\mathrm{CrCl}_{3}\right)$ and a liquid metal, a redox couple $\mathrm{Cr}^{0}-\mathrm{Cr}(\mathrm{III})$. The magnitude of isotope fractionation in this experiment was under the detection limit of MC-TIMS (Fujii et al, 2006a), but could be identified by MC-ICP-MS (Fujii et al., 2007). The mass-independent isotope fractionation associated with this high temperature redox reaction is consistent with a nuclear field shift effect. This would be correlated with the presence or absence of a $4 s$ electron in the redox system.

\subsection{Iron}

There is no evidence of the mass-independent isotope fractionation of $\mathrm{Fe}\left({ }^{54} \mathrm{Fe},{ }^{56} \mathrm{Fe}\right.$, ${ }^{57} \mathrm{Fe}$, and ${ }^{58} \mathrm{Fe}$ ) (see a review by Dauphas and Rouxel, 2006). A simple explanation is that $\left\langle r^{2}\right\rangle$ is nearly linearly with mass (Fricke and Heilig, 2004) (see Fig. 5e). Even with a high precision analysis (Fujii et al., 2006b), the method based on Eq. 31 cannot 
595

596

597

598

599

600

601

602

606

607

608

609

610

611

612

613

identify any mass-independent isotope effects (Fig. 11). The method based on Eq. 32 might be more suitable for Fe isotopes, but the relevant data are still missing.

\subsection{Nickel}

Nickel has five naturally occurring isotopes $\left({ }^{58} \mathrm{Ni},{ }^{60} \mathrm{Ni},{ }^{61} \mathrm{Ni},{ }^{62} \mathrm{Ni}\right.$, and $\left.{ }^{64} \mathrm{Ni}\right)$. The $<r^{2}>$ 's of Ni also show only subtle odd-even staggering (Fig. 5f). Ni isotopes were fractionated by a liquid-liquid extraction system by Nishizawa et al. (1997). Isotope enrichment factors show an odd-even staggering trend, but the experimental errors are quite large. These experiments should be re-examined in view of the recent high precision $\mathrm{Ni}$ isotopic data acquired by MC-ICP-MS (Dauphas et al., 2008; Moynier et al., 2007b, Quitté et al., 2007; Bizzarro et al. 2007; Regelous et al., 2008).

\subsection{Zinc}

Zinc has five naturally occurring isotopes $\left({ }^{64} \mathrm{Zn},{ }^{66} \mathrm{Zn},{ }^{67} \mathrm{Zn},{ }^{68} \mathrm{Zn}\right.$, and $\left.{ }^{70} \mathrm{Zn}\right)$. Their charge radii show a clear odd-even staggering (Fig. 5g). Mass-independent isotope fractionation was first observed for ${ }^{67} \mathrm{Zn}$ in a chemical exchange reaction using crown ether (Nishizawa et al., 1993). These early isotopic analyses were performed on an ICP quadrupole mass spectrometer at rather low precision, but were later confirmed on TIMS by Nishizawa et al. (1996, 1998a). The most recent investigations used MC-ICP-MS (Nishizawa et al, 1998b; Fujii et al., 2001a). Because of an isotopic interference of the ${ }^{64} \mathrm{Ni}^{+}$beam, presumably emitted by the sampler and skimmer cones of the mass spectrometer, ${ }^{64} \mathrm{Zn}$ is neglected in these studies. A clear odd-even staggering was observed (Fig. 12).

Chromatographic experiments have also been run on crown ether resins (Ban et 
619 al., 2002; Zhang et al., 2006; Fukuda et al., 2006). The isotope enrichment factors are 620 mass-dependent within experimental errors, but odd-even staggering is permitted by the 621 results (0.3-0.6\% deviation from the mass-dependent line, Zhang et al., 2006).

\subsection{Strontium}

624 Strontium has four naturally occurring isotopes $\left({ }^{84} \mathrm{Sr},{ }^{86} \mathrm{Sr},{ }^{87} \mathrm{Sr}\right.$, and $\left.{ }^{88} \mathrm{Sr}\right)$. Strontium isotope fractionation by chemical exchange reactions has been investigated by various research groups (Oi, et al., 1992; Nishizawa et al., 1994; 1995; Ban, et al., 2001; Shibahara et al., 2002b,c, 2003, 2006). On cation-exchange resins, the isotope separation factor per unit mass difference seems to be extremely small, $\sim 1.000001$ (Oi et al., 1992). Chromatographic systems in which macrocyclic compounds (crown ether and cryptand) are employed as the stationary phase improve the isotope separation factor by 100 times or more (Ban, et al., 2001; Shibahara et al., 2002b, 2003, 2006). Solvent extraction systems using a macrocyclic compound as an extractant also give large isotope separation factors (Nishizawa et al., 1994; 1995; Shibahara et al., 2002c). Nishizawa et al. (1995) observed odd/even isotope staggering and a correlation between $\varepsilon$ and $\left\langle r^{2}>\right.$ (Fig. 13). The correlation is consistent with a nuclear field shift effect. A subsequent investigation (Shibahara et al., 2002c) supported it. liquid chromatography with a cryptand stationary phase (Shibahara et al., 2002b, 2003, 2006). Isotopic abundances were analyzed by ICP-QMS, which makes the discussion of mass-independent isotope fractionation less certain. Ban et al. (2001) reported mass-dependent isotope fractionation of $\mathrm{Sr}$ by liquid chromatography with a crown ether as the stationary phase. A hint of mass-independent fractionation, however, can be 
643

644

645

646

found in a sample (for example, sample D23).

\subsection{Zirconium}

Though mass-independent fractionations have been found in a liquid-liquid extraction system (Fujii et al., 1998b), their profile did not show a simple dependence on $<r^{2}>$ (Fig. 5i).

\subsection{Molybdenum}

Molybdenum has seven naturally occurring isotopes, five even $\left({ }^{92} \mathrm{Mo},{ }^{94} \mathrm{Mo},{ }^{96} \mathrm{Mo},{ }^{98} \mathrm{Mo}\right.$, and $\left.{ }^{100} \mathrm{Mo}\right)$ and two odd $\left({ }^{95} \mathrm{Mo}\right.$ and $\left.{ }^{97} \mathrm{Mo}\right)$. Molybdenum isotopes were fractionated by liquid-liquid extraction (Fujii et al, 2006c). The aqueous phase was $\mathrm{Mo}(\mathrm{VI})$ in $\mathrm{HCl}$ and the organic phase was a dichloroethane solution containing a crown ether. Isotopic analyses were performed by MC-ICP-MS with a precision of $<100 \mathrm{ppm}$. Odd-even staggering correlated with $\left\langle r^{2}\right\rangle$ (Fig. 5j) was observed. Mass-independent isotope fractionation was most conclusive in $5.4 \mathrm{M} \mathrm{HCl}$ (Fig. 14). The contributions of the nuclear field shift effect and the mass effect were evaluated with Eq. 31. Figure 15a shows the dependence of these contributions on $\mathrm{HCl}$ concentration. Mass-dependent effects are predominant in concentrated acids, whereas the nuclear field shift effect was most visible at $\mathrm{HCl}$ molalities $<6.5 \mathrm{M}$.

\subsection{Ruthenium}

Ruthenium has seven naturally occurring isotopes, five even $\left({ }^{96} \mathrm{Ru},{ }^{98} \mathrm{Ru},{ }^{100} \mathrm{Ru},{ }^{102} \mathrm{Ru}\right.$, and $\left.{ }^{104} \mathrm{Ru}\right)$ and two odd $\left({ }^{99} \mathrm{Ru}\right.$ and $\left.{ }^{101} \mathrm{Ru}\right)$. Ruthenium isotopes were fractionated under conditions similar to those described for Mo (Fujii et al., 2006c). Odd-even staggering 
667 correlated with $\left\langle r^{2}>\right.$ (Fig. 5k) can again be observed. ${ }^{96} \mathrm{Ru}$ and ${ }^{98} \mathrm{Ru}$ are neglected of the 668 discussion because of their small abundances. Mass-independent isotope fractionation 669 was found at high $\mathrm{HCl}$ molarity (Fig. 16). As with Mo, the relative contributions of the 670 nuclear field shift and mass effects (Fig. 15b) depend on $\mathrm{HCl}$ concentration.

Tellurium has eight naturally occurring isotopes, six even $\left({ }^{120} \mathrm{Te},{ }^{122} \mathrm{Te},{ }^{124} \mathrm{Te},{ }^{126} \mathrm{Te},{ }^{128} \mathrm{Te}\right.$, and $\left.{ }^{130} \mathrm{Te}\right)$ and two odd $\left({ }^{123} \mathrm{Te}\right.$ and $\left.{ }^{125} \mathrm{Te}\right)$. Tellurium isotopes were fractionated under the same condition as Mo and Ru (Moynier et al, 2008). Odd-even staggering was observed to correlate with $<r^{2}>$ (Fig. 51). This suggests that fractionation of the odd atomic mass isotope ${ }^{125} \mathrm{Te}$ deviates from the mass-dependent trend defined by the even atomic isotopes (Fig. 17), and therefore should not be used for normalization (Fehr et al., 2006).

\subsection{Barium}

682

683

Barium has seven naturally occurring isotopes, five even $\left({ }^{130} \mathrm{Ba},{ }^{132} \mathrm{Ba},{ }^{134} \mathrm{Ba},{ }^{136} \mathrm{Ba}\right.$, and $\left.{ }^{138} \mathrm{Ba}\right)$ and two odd $\left({ }^{135} \mathrm{Ba}\right.$ and $\left.{ }^{137} \mathrm{Ba}\right) .{ }^{130} \mathrm{Ba}$ and ${ }^{132} \mathrm{Ba}$ are less abundant isotopes. $\left\langle r^{2}\right\rangle$ values of $\mathrm{Ba}$ isotopes show prominent odd-even staggering (Fig. 18a is reproduced from Fig. 5m). There have been several studies of isotope fractionation of $\mathrm{Ba}$ in chemical exchange reactions. These data (Nishizawa et al., 1994; Kondoh et al., 1996; Chang et al., 1996; Shibahara et al., 2002a; Ban, 2002) are shown in Figs. 18b-f. In each system, odd atomic mass isotopes are less fractionated than adjacent even atomic mass isotopes, consistent with a nuclear field shift effect. 
691

692

693

694

695

696

697

698

\subsection{Lanthanides (cerium, neodymium, samarium, gadolinium, and ytterbium)}

Cerium has no stable odd atomic mass isotopes $\left({ }^{136} \mathrm{Ce},{ }^{138} \mathrm{Ce},{ }^{140} \mathrm{Ce}\right.$, and $\left.{ }^{142} \mathrm{Ce}\right)$. Thus odd-even staggering cannot be documented. ${ }^{140} \mathrm{Ce}$ possesses a magic number of neutron, 82. The variation of $\left\langle r^{2}>\right.$ with isotopic mass is shown in Fig. 5n. Zhang et al. (2005) reported an unusual fractionation of Ce isotopes on a cation-exchange column (Fig. 19), but admitted uncertainty about possible Ba isobaric interferences at masses 136 and 138 . Ce is a heavy element, the $\left\langle r^{2}>\right.$ of the four isotopes varies and their nuclear spins are all zero. Hence, $\mathrm{Ce}$ is an ideal candidate to investigate the nuclear field shift effect. Achieving high precision for isotopic analysis is hampered by the small abundance of ${ }^{136} \mathrm{Ce}$ and ${ }^{138} \mathrm{Ce}$, and the potential isobaric interferences of ${ }^{136} \mathrm{Ba}$ and ${ }^{138} \mathrm{Ba}$ (and ${ }^{138} \mathrm{La}$ ).

A strong increase of isotope shifts (Brix and Kopfermann, 1958) and $<r^{2}>$ (Kuhn, 1969) has been pointed out starting around neutron number 90 (Figs. 5o-q). Isotope pairs with neutrons 88 and 90 include ${ }^{148} \mathrm{Nd}-{ }^{150} \mathrm{Nd},{ }^{150} \mathrm{Sm}-{ }^{152} \mathrm{Sm}$, and ${ }^{152} \mathrm{Gd}-{ }^{154} \mathrm{Gd}$. For example, it has long been known that the three even atomic mass isotopes ${ }^{150} \mathrm{Sm},{ }^{152} \mathrm{Sm}$, and ${ }^{154} \mathrm{Sm}$ do not give equidistant lines in atomic spectra (Schüler, and Schmidt, 1934; Herzberg, 1944) and this gave rise to the suggestion that the nuclear shape needed to be taken into account to explain isotopic shifts (Brix and Kopfermann, 1949). Nuclear deformation around neutron number 90 is discussed in the literature (Stacy, 1966; Kurn, 1969; King, 1984). In a series of separation studies of Nd, Sm, and Gd isotopes using iquid-liquid extraction (Fujii et al., 1998c, 1999, 2000), isotope fractionation has been found to be strongly mass-independent for these isotope pairs (Fig. 20a and Fig. 21a). This effect was only tested for even atomic mass isotopes whose nuclear spins are zero, and hence, the finding strengthens confidence in the importance of the nuclear field shift effect. 
The separation of $\mathrm{Sm}$ isotopes has also been investigated by equilibrating amalgam with aqueous solutions (Dembiński et al., 1998, 2001). Fractionation patterns are consistent with nuclear field shift effects. An odd-even staggering of Sm isotope fractionation was also found in crown ether systems (Fig. 20a) (Fujii et al., 1998c). In contrast, odd-even staggering cannot be identified in the amalgam experiments of

Dembiński et al. (2001) (Fig. 20b). However, $\varepsilon^{\prime}$ s of even atomic mass isotopes $\left({ }^{148} \mathrm{Sm}\right.$, ${ }^{150} \mathrm{Sm},{ }^{152} \mathrm{Sm}$, and ${ }^{154} \mathrm{Sm}$ ) do not follow a mass-dependent line (Fig 20b).

Odd-even staggering in $\mathrm{Yb}$ isotope fractionation was observed in the experiments of Dembiński $(1998,2001)$. The odd-even staggering was also reported previously by Chen et al. (1992) for ${ }^{157} \mathrm{Gd}$ and later by Ismail et al. (2000) for ${ }^{155} \mathrm{Gd}$ and ${ }^{157} \mathrm{Gd}$ (Fig. 21b) who attributed the staggering to nuclear field shift effects.

\subsection{Hafnium}

The separation of Hf isotopes has been investigated in liquid-liquid extraction systems with various extractants (Fujii et al., 2001b). No isotope fractionation was observed among even isotopes $\left({ }^{178} \mathrm{Hf}\right.$ and $\left.{ }^{180} \mathrm{Hf}\right)$, but an effect was observed for the isotopes ${ }^{177} \mathrm{Hf}$ and ${ }^{179}$ Hf. It was suggested by the authors that the effect may result from the difference of nuclear spins, $I=7 / 2$ for ${ }^{177} \mathrm{Hf}$ and $9 / 2$ for ${ }^{179} \mathrm{Hf}$.

\subsection{Actinides (Uranium)}

The history of the uranium isotope separation by chemical exchange has been reviewed elsewhere (Bigeleisen, 1992, 2006; Ishida and Fujii, 2006). The nuclear field shift effect was found in the unusual isotope enrichment of ${ }^{235} \mathrm{U}$ in a redox system (Fujii et al., 1989a,b). Their results are shown in Fig. 22 (for comparison, $<r^{2}>$ profile is shown in 
739

Fig. 5t). This finding prompted an update of the classic theory (Urey, 1947; Bigeleisen and Mayer, 1947) by Bigeleisen (1996a) and Nomura et al. (1996). The relative importance of quadrupole terms in the nuclear field shift of these isotopes was found by Knyazev $(1999,2001)$ to be as large as 20 percent of the mean effect of nuclear size and shape. The contribution of Bigleisen's (1996) theory to the uranium isotope separation was reviewed by Mioduski (1999). In the most recent studies on $a b$ initio molecular orbital calculation (Abe at al., 2008a,b), the nuclear field shift effect found by Fujii et al. (1989a,b) was reproduced.

In the latest studies, the nuclear field shift effects of Cd (Fujii et al., 2009) and Sn (Moynier et al., 2009) have been found.

\section{Summary}

Over a decade has passed since Bigeleisen formulated his theory of the nuclear field shift effect. With the advent of very precise mass spectrometers and the development of computer simulations, experimental evidence of the ubiquity of the nuclear field shift is increasing while at the same time the theoretical understanding of this process is becoming stronger. The nuclear field shift effect is a suitable explanation of mass-independent isotope fractionation in many equilibrium systems. By further exploring the concepts laid out by Bigeleisen and their consequences, a better understanding of mass-independent isotope fractionation should be achieved.

\section{Acknowledgment}

The authors thank Edwin Schauble, an anonymous reviewer, the guest editor, Mathieu 
763 Roskosz, and the editor, Bernard Bourdon, for useful suggestions and constructive

764 comments on the manuscript. TF thanks Masabumi Miyabe for his valuable comments

765 to the nuclear spin effect and Roy Jacobus for his help in improving the English of the

766 manuscript.

767 


\section{References}

Abe, M., Suzuki, T., Fujii, Y., Hada, M., 2008a. An ab initio study based on a finite nucleus model for isotope fractionation in the U(III)-U(IV) exchange reaction system. J. Chem. Phys. 128, 144309.

Abe, M., Suzuki, T., Fujii, Y., Hada, M., Hirao, K., 2008b. An ab initio molecular orbital study of the nuclear volume effects in uranium isotope fractionations. J. Chem. Phys. $129,164309$.

Angeli, I., 2004. A consistent set of nuclear rms charge radii: properties of the radius surface $R(N, Z)$. Atom. Data Nucl. Data Tables 87, 185-206.

Atkins, P. W., 1998. Physical Chemistry. 6th ed. Oxford University Press, Oxford.

Aufmuth, P., Heilig, K., Steudel, A., 1987. Changes in mean-square nuclear charge radii from optical isotope shifts. At. Data Nucl. Data Tables 37, 455-490.

Ban, Y., Nomura, M., Fujii, Y., 2001. Isotope effects of strontium in crown ether chromatography, Sep. Sci. Technol. 36, 2165-2180.

Ban, Y., 2002. Doctoral thesis, Tokyo Institute of Technology, Japan (in Japanese).

Ban, Y., Nomura, M., Fujii, Y., 2002. Isotope effects of zinc in crown ether chromatography. J. Nucl. Sci. Technol. 39, 156-159.

Bergquist, B. A., Blum, J. D., 2007. Mass-dependent and -independent fraction of $\mathrm{Hg}$ isotopes by photoreduction in aquatic systems. Science 318, 417-420.

Bigeleisen, J., Mayer, M. G., 1947. Calculation of equilibrium constants for isotopic exchange reactions. J. Chem. Phys. 15, 261-267.

Bigeleisen, J., 1992. History and theory of uranium isotope enrichment by chemical exchange. Bull. Res. Lab. Nucl. React. 16 (special issue 1), 3-17.

Bigeleisen, J., 1996a. Nuclear size and shape effects in chemical reactions. Isotope chemistry of the heavy elements. J. Am. Chem. Soc. 118, 3676-3680.

Bigeleisen, J., 1996b. Temperature dependence of the isotope chemistry of the heavy elements. Proc. Natl. Acad. Aci. USA 93, 9393-9396.

Bigeleisen, J., 1998. Second-order correction to the Bigeleisen-Mayer equation due to the nuclear field shift. Proc. Natl. Acad. Aci. USA 95, 4808-4809.

Bigeleisen, J., 2006. Theoretical basis of isotope effects from an autobiographical perspective. in Isotope Effects in Chemistry and Biology (Kohen, A., Limbach, H.-H., eds.), pp. 1-39, Taylor \& Francis, Boca Raton.

Bizzarro, M., Ulfbeck, D., Trinquier, A., Thrane, K., Connelly, J. N., Meyer, B. S. 2007. Evidence for a late supernova injection of ${ }^{60} \mathrm{Fe}$ into the protoplanetary disk. Science 316, 1178-1181. 
Breit, G., 1958. Theory of isotope shift. Rev. Mod. Phys. 30, 507-517.

Brix. P., Kopfermann, H., 1949. Zur isotopieverschiebung im spektrum des samariums. Z. Phys. B 126, 344-364.

Brix. P., Kopfermann, H., 1958. Isotope shift studies of nuclei. Rev. Mod. Phys. 30, 517-520.

Buchachenko, A. L., 1977. Enrichment of magnetic isotopes - New method of investigation of chemical reaction mechanisms. Russian J. Phys. Chem. 51, 1445-1451.

Buchachenko, A. L., 1995. MIE versus CIE: Comparative analysis of magnetic and classical isotope effects. Chem. Rev. 95, 2507-2528.

Buchachenko, A. L., 2000. Recent advance in spin chemistry. Pure Appl. Chem. 72, 2243-2258.

Buchachenko, A. L., 2009. Magnetic isotope effects in chemistry and biochemistry. Wiley Interscience, New York.

Chang, Z., Nomura, M., Motomiya, K., Fujii, Y., 1996. Isotope effects of barium in amalgam/aqueous hydroxide solution systems. J. Chem. Soc., Faraday Trans. 92, 4485-4489.

Chen, J. R., Nomura, M., Fujii, Y., Kawakami, F., Okamoto, M., 1992. Gadolinium isotope separation by cation exchange chromatography. J. Nucl. Sci. Technol. 29, 1086-1092.

Dauphas. N., Rouxel, O., 2006. Mass spectrometry and natural variations of iron isotopes. Mass Spectrom. Rev. 25, 515-550.

Dauphas, N., Cook, D. L., Sacarabany, A., Fröhlich, C., Davis, A. M., Wadhwa, M., Pourmand, A., Rauscher, T., Gallino, R., 2008. Iron 60 evidence for early injection and efficient mixing of stellar debris in the protosolar nebula. Astrophys. J. 686, 560-569.

Dembiński, W., Poniński, M., Fiedler, R., 1998. Preliminary results of the studies on fractionation of ytterbium isotopes in $\mathrm{Yb}(\mathrm{III})$-acetate/Yb-amalgam system. Sep. Sci. Technol. 33, 1693-1701.

Dembiński, W., Poniński, M., Fiedler, R., 2001. Isotope effects of samarium and ytterbium in the acetate/amalgam separation system. J. Radioanal. Nucl. Chem. 250, 423-428

Farquhar, J., Bao, H., Thiemens, M., 2000. Atmospheric influence of earth's earliest sulfur cycle. Science $289,756-758$.

Fehr, M. A., Rehkamper, M., Halliday, A. N., Schonbachler, M., Hattendorf, B., Gunther, D., 2006., Search for nucleosynthetic and radiogenic tellurium isotope anomalies in carbonaceous chondrites. Geochim. Cosmochim. Acta 70, 3436-3448. 
Fricke, G., Heilig, K., 2004. Nuclear Charge Radii (Landolt-Bornstein Numerical Data and Functional Relationships in Science and Technology - New Series) (H. Schopper, ed.), Springer, Berlin.

Fujii, T., Inagawa, J., Nishizawa, K., 1998a. Influences of nuclear mass, size, shape and spin on chemical isotope effect of titanium. Ber. Bunsenges. Phys. Chem. 102, $1880-1885$.

Fujii, T., Yamamoto, T., Inagawa, J., Watanabe, K., Nishizawa, K., 1998b. Influences of nuclear size and shape and nuclear spin on chemical isotope effect of zirconium-crown complex. Ber. Bunsenges. Phys. Chem. 102, 663-669.

Fujii, T., Yamamoto, T., Nishizawa, K., Inagawa, J., Gunji, K., Watanabe, K., , 1998c. Separation of samarium isotopes by a crown ether. Sovent Ext. Ion Exch. 16, 985-999.

Fujii, T., Yamamoto, T., Inagawa, J., Gunji, K., Watanabe, K., Nishizawa, K., 1999. Nuclear size and shape effect in chemical isotope effect of gadolinium using dicyclohexano-18-crown-6. Sovent Ext. Ion Exch. 17, 1219-1229.

Fujii, T., Yamamoto, T., Inagawa, J., Gunji, K., Watanabe, K., Nishizawa, K., 2000. Nuclear size and shape effect in chemical isotope enrichment of neodymium using dicyclohexano-18-crown-6. Sovent Ext. Ion Exch. 18, 1155-1166.

Fujii, T., Hirata, T., Shibahara, Y., Nishizawa, K., 2001a. Mass-dependent and mass-independent isotope effects of zinc in chemical exchange reactions using liquid chromatography with a cryptand stationary phase. Phys. Chem. Chem. Phys. 3, 3125-3129.

Fujii, T., Moriyama H., Hirata, T., Nishizawa, K., 2001b. Isotope effects of hafnium in solvent extraction using crown ethers. Bull. Chem. Soc. Jpn. 74, 1031-1032.

Fujii, T., Suzuki, D., Gunji, K., Watanabe, K., Moriyama, H., Nishizawa, K., 2002. Nuclear field shift effect in the isotope exchange reaction of chromium(III) using a crown ether. J. Phys. Chem. A 106, 6911-6914.

Fujii, T., Suzuki, D., Watanabe, K., Yamana, H., 2006a. Application of the total evaporation technique to chromium isotope ratio measurement by thermal ionization mass spectrometry. Talanta 69, 32-36.

Fujii, T., Moynier. F, Telouk, P., Albarède, F. 2006b. Isotope fractionation of iron(III) in chemical exchange reactions using solvent extraction with crown ether. J. Phys. Chem. A 110, 11108-11112.

Fujii, T., Moynier. F, Telouk, P., Albarède, F. 2006c. Mass-independent isotope fractionation of molybdenum and ruthenium and the origin of isotopic anomalies in Murchison. Astrophys. J. 647, 1506-1516.

Fujii, T., Moynier, F., Yin, Q-Z., 2007. Mass-independent isotope fractionation of chromium in ligand exchange reaction and redox reaction. Lunar Planet. Sci. Conf. $38,1213$. 
Fujii, T., Moynier, F., Yin, Q-Z., Yamana, H., 2008a. Mass-independent isotope fractionation in the chemical exchange reaction of chromium(III) using a crown ether. J. Nucl. Sci. Technol. suppl. 6, 6-9.

Fujii, T., Suzuki, D., Yamana, H., 2008b. Nuclear field shift effect of chromium(III) in repeated extraction using a crown ether. Solvent Extr. Ion Exch. 26, 100-112.

Fujii, T., Moynier. F, Telouk, P., Albarède, F., 2009. Nuclear field shift effect in the isotope exchange reaction of cadmium using a crown ether. Chem. Geol. doi:10.1016/j.chemgeo.2008.12.004.

Fujii, Y., Hoshi, J., Iwamoto, H., Okamoto, M., Kakihana, H., 1985. Calcium isotope effects in ion exchange electromigration and calcium isotope analysis by thermo-ionization mass spectrometry. Z. Naturforsch. 40a, 843-848.

Fujii, Y., Nomura, M., Okamoto, M., Onitsuka, H., Kawakami, F., Takeda, K., 1989a. An anomalous isotope effect of ${ }^{235} \mathrm{U}$ in $\mathrm{U}(\mathrm{IV})-\mathrm{U}(\mathrm{VI})$ chemical exchange. $\mathrm{Z}$. Naturforsch. A 44, 395-398.

Fujii, Y., Nomura, M., Onitsuka, H., Takeda, K., 1989b. Anomalous isotope fretionation in uranium enrichment process. J. Nucl. Sci. Technol. 26, 1061-1064.

Fukuda, Y., Zhang, Y. -H., Suzuki, T., Fujii, Y., Oi, T., 2006. Zinc isotope accumulation in liquid chromatography with crown ether resin. J. Nucl. Sci. Technol. 43, 446-449.

Glueckauf, E., 1955. Theory of chromatography. Part 9. The "theoretical plate" concept in column separations. Trans. Faraday Soc. 51, 34-44.

Hathorn, B. C. Marcus, B. C., 1999. An intramolecular theory of the mass-independent isotope effect for ozone. I. J. Chem. Phys. 111, 4087-4100.

Heilig, K., Steudel, A., 1978. in Progress in Atomic Spectroscopy (W. Hanle and H. Kleinpoppen, eds.), Part A, pp. 263-328, Plenum Press, New York.

Herzberg, G., 1944. Atomic spectra and atomic structure. Dover Publications, New York.

Heumann, K. G., Schiefer, H. -P., 1980. Calcium isotope separation on an exchange resin having cryptand anchor groups. Angew. Chem. Int. Ed. Engl. 19, 406-407.

Heumann, K. G., Schiefer, H. -P., Spiess, W., 1982. Enrichment of heavy calcium isotopes by ion exchange resins with cyclopolyethers as anchor groups. in Stable Isotopes (Schiefer, H. -P., Förstel, H., Heinzinger, K., eds.), pp. 711-718, Elsevier, Amsterdam.

Heumann, K. G., 1985. Isotopic separation in systems with crown ethers and cryptands. in Topics in Current Chemistry (K. Meurer, ed.), vol. 127, pp. 77-132, Springer, Berlag.

Hutchison, C. A., Stewart, D. W., Urey, H. C., 1940. The concentration of $C^{13}$. J. Chem. Phys. 8, 532-537. 
Ishida, T. 2002. Isotope effect and isotope separation: A chemist's view. J. Nucl. Sci. Technol. 39, 407-412.

Ishida, T., Fujii Y., 2006. Enrichment of isotopes. in Isotope Effects in Chemistry and Biology (Kohen, A., Limbach, H.-H., eds.), pp. 41-87, Taylor \& Francis, Boca Raton.

Ismail, I. M., Fukami, A., Nomura, M., Fujii, Y., 2000. Anomaly of ${ }^{155} \mathrm{Gd}$ and ${ }^{157} \mathrm{Gd}$ isotope effects in ligand exchange reactions observed by ion exchange chromatography. Anal. Chem. 72, 2841-2845.

Jepson, B. E., Shockey, G. C., 1984. Calcium hydroxide isotope effect in calcium isotope enrichment by ion exchange. Sep. Sci. Technol., 19, 173-181.

Jepson, B. E., Cairns, G. A., 1979. Lithium isotope effects in chemical exchange with $(2,2,1)$ cryptand. MLM-2622.

Kakihana H., Kanzaki T., 1969. A simplified and generalized method for analyzing chromatographic isotope separation fata. Bull. Tokyo Inst. Technol., 90, 77-89.

Kawashiro. F., Fujii, T., Nishizawa, K., 1998. Mass-independent isotope effects in chemical exchange reaction. Chromium isotope enrichment by a crown ether. in Proc. Sep. Phenomena Liq. Gases (Yamamoto, I., ed), pp.391-399, Nagoya Univ.

Khudyakov, I. V., Serebrennikov, Y. A., Turro, N. J., 1993. Spin-orbit coupling free radical reactions: On the way to heavy elements. 93, 537-570.

King, W. H., 1984. Isotope shifts in atomic spectra. Plenum Press, New York.

Kleinman L. I., Wolfsberg. M., 1973. Corrections to Born-Oppenheimer approximation and electronic effects on isotopic-exchange equilibria. J. Chem. Phys. 59, 2043-2053.

Kleinman L. I., Wolfsberg. M., 1974a. Corrections to Born-Oppenheimer approximation and electronic effects on isotopic-exchange equilibria. II. J. Chem. Phys. 60, $4740-4748$.

Kleinman L. I., Wolfsberg. M., 1974b. Shifts in vibrational constants from corrections to Born-Oppenheimer approximation: Effects on isotopic-exchange equilibria. J. Chem. Phys. 60, 4749-4754.

Knyazev, D. A., Semin, G. K., Bochkarev, A. V., 1999. Nuclear quadrupole contribution to the equilibrium isotope effect. Polyhedron 18, 2579-2582.

Knyazev, D. A., Myasoedov, N. F., 2001. Specific effects of heavy nuclei in chemical equilibrium. Sep. Sci. Technol., 36, 1677-1696.

Kondoh, A., Oi, T., Hosoe, M., 1996. Fractionation of barium isotopes in cation-exchange chromatography. Sep. Sci. Technol. 31, 39-48.

Kotaka, M., Okamoto, M., Bigeleisen, J., 1992. Anomalous mass effects in isotopic exchange equilibria. J. Am. Chem. Soc. 114, 6436-6445.

Kurn, H. G., 1969. Atomic spectra. Longman's, London. 
Lawler, R. G., Evans, G. T., 1971, Some chemical consequences of magnetic interactions in radical pairs. Ind. Chim. Belg. 36, 1087-1089.

London, H. 1961. Separation of isotopes. George Newnes Limited, London.

Mioduski, T., 1999. Comment to the Bigeleisen's theory of isotope chemistry of the heavy elements. Comments Inorg. Chem. 21, 175-196.

Minkin, V. I., 1999. Glossary of terms used in theoretical organic chemistry. Pure Appl. Chem. 10, 1919-1981.

Moynier, F., Yin, Q-Z., Jacobsen, B., 2007a. Dating the first stage of planet formation. Astrophys. J. Lett. 671, L181-L183.

Moynier, F., Blichert-Toft, J., Telouk, P., Luck J.-M., Albarède, F., 2007b. Comparative stable isotope geochemistry of $\mathrm{Ni}, \mathrm{Cu}, \mathrm{Zn}$, and $\mathrm{Fe}$ in chondrites and iron meteorites. Geochim. Cosmochim. Acta 71, 4365-4379.

Moynier, F., Fujii, T., Telouk, P., Albarède, F., 2008. Isotope separation of Te in chemical exchange system with dicyclohexano-18-crown-6. J. Nucl. Sci. Technol. suppl. $6,10-14$.

Moynier, F., Fujii, T., Telouk, P., 2009. Mass-independent isotopic fractionation of tin in chemical exchange reaction using a crown ether. Anal. Chim. Acta. 632, 234-239.

Nishizawa, K., Ishino. S., Watanabe, H., Shinagawa, M., 1984. Lithium isotope separation by liquid-liquid extraction using benzo-15-crown-5. J. Nucl. Sci. Technol. 21, 694-701.

Nishizawa, K., Nakamura, K., Yamamoto, T., Masuda, T., 1993. Zinc isotope effects in complex-formation with a crown-ether. Solvent Extr. Ion Exch. 11, 389-394.

Nishizawa, K., Nakamura, K., Yamamoto, T., Masuda, T., 1994. Separation of strontium and barium isotopes using a crown-ether. Different behaviors of odd mass and even mass isotopes. Solvent Extr. Ion Exch. 12, 1073-1084.

Nishizawa, K., Satoyama, T., Miki, T., Yamamoto, T., Hosoe, M., 1995. Strontium isotope effect in liquid-liquid extraction of strontium chloride using a crown ether. J. Nucl. Sci. Technol. 32, 1230-1235.

Nishizawa, K., Satoyama, T., Miki, T., Yamamoto, T., Nomura, M., 1996. Separation of zinc isotopes by liquid-liquid extraction using a crown ether. Sep. Sci. Technol. 31, 2831-2841.

Nishizawa, K., Miki, T., Ikeda, R., Fujii, T., Yamamoto, T., Nomura, M., 1997. Isotopic enrichment of nickel in aqueous solution/crown ether system. J. Mass Spectrom. Soc. Jpn. 45, 521-527.

Nishizawa, K., Miki, T., Satoyama, T., Fujii, T., Yamamoto, T., Nomura, M., 1998a. Enrichment of zinc isotopes by a liquid membrane system using a crown ether. Sep. Sci. Technol. 33, 991-1002. 
Nishizawa, K., Maeda, Y., Kawashiro, F., Fujii, T., Yamamoto, T., Hirata, T., 1998b. Contributions of nuclear size and shape, nuclear mass, and nuclear spin to enrichment factors of zinc isotopes in a chemical exchange reaction by a cryptand. Sep. Sci. Technol. 33, 2101-2112.

Nomura, M., Higuchi, N., Fujii, Y., 1996. Mass dependence of uranium isotope effects in the U(IV)-U(VI) exchange reaction. J. Am. Chem. Soc. 118, 9127-9130.

Oi, T., Ogino, H., Hosoe, M., Kakihana, H., 1992. Fractionation of strontium isotopes in cation-exchange chromatography. Sep. Sci. Technol. 27, 631-643.

Oi, T., Morioka, N., Ogino, H., Kakihana, H., Hosoe, M., 1993. Fractionation of calcium isotopes in cation-exchange chromatography. Sep. Sci. Technol. 28, 1971-1983.

Quitté, G., Halliday, A. N., Meyer, B. S., Markowski, A., Latkoczy, C., Günther, D., 2007. Correlated iron 60, nickel 62, and zirconium 96 in refractory inclusions and the origin of the solar system. Astrophys. J. 655, 678-684.

Rai, V. K., Thiemens M. H., 2007. Mass independently fractionated sulfur components in chondrites. Geochim. Cosmochim. Acta 71, 1341-1354.

Regelous, M., Elliott, T., Coath, C. D., 2008. Nickel isotope heterogeneity in the early Solar System. Earth Planet. Sci. Lett. 272, 330-338.

Rykov, S. V., Khudyakov, I. V., Skakovsky, E. D., Tychinskaya, L. Yu., Ogorodnikova, M. M. 1992. Magnetic and spin effects furing dioxouranium(VI) sussinate photolysis. J. Photochem. Photobiol. A 66, 127-130.

Salikhov, K. M., 1996. Magnetic isotope in radical reactions. Springer, Verlag/Wien.

Schauble, E. A., 2007. Role of nuclear volume in driving equilibrium stable isotope fractionation of mercury, thallium, and other very heavy elements, Geochim. Cosmochim. Acta 71, 2170-2189.

Schlembach, J., Tiemann, E., 1982. Isotope field shift of the rotational energy of the $\mathrm{Pb}$-chalcogenides and Tl-halides. Chem. Phys. 68, 21-28.

Schüler, H., Schmidt, Th., 1934. Über eine neue erscheinung bei den isotopen des samariums. Z. Phys. 92, 148-152.

Shibahara, Y., Nomura, M., Hamanishi, E., Suzuki, K., Fujii, T., 2002a. Temperature dependence of isotope effects of barium using a crown ether, (II). Barium isotope effects in $\mathrm{BaCl}_{2} / \mathrm{DC} 18 \mathrm{C} 6$ systems. J. Nucl. Sci. Technol. 39, 938-940.

Shibahara, Y., Nishizawa, K., Yasaka, Y., Fujii, T., 2002b. Strontium isotope effect in DMSO-water system by liquid chromatography using a cryptand polymer. Solvent Extr. Ion Exch., 20, 67-79.

Shibahara, Y., Takaishi, H., Nishizawa, K., Fujii, T., 2002c. Strontium isotope effects in ligand exchange reaction. J. Nucl. Sci. Technol. 39, 451-456. 
Shibahara, Y., Nishizawa, K., Yasaka, Y., Fujii, T., 2003. Effect of counter anion in isotope exchange reaction of strontium, Solvent Extr. Ion Exch., 21, 435-448.

Shibahara, Y., Yasaka, Y., Izumi, Y., Ema, K., Takeda, S., Nishijima, S., Fujii, T., 2006. Solvent effect in isotope exchange reaction of strontium by liquid chromatography using a cryptand $\left(2_{\mathrm{B}}, 2,2\right)$ polymer, Solvent Extr. Ion Exch., 24, 915-929.

Spedding, F. H., Powell, J. E., Svec, H. J., 1955. A laboratory method for separating nitrogen isotopes by ion exchange. J. Am. Chem. Soc. 77, 6125-6132.

Stacey, D. N., 1966. Isotope shifts and nuclear charge distributions, Rep. Prog. Phys. 29, 171-215.

Step, E. N., Buchachenko, A. L., Turro, N. J., 1992. Magnetic effects in the photolysis of micellar solutions of phenacylphenylsulfone. Chem. Phys. 162, 189-204.

Stern R. C., Snavely B. B., 1976. The laser isotope separation program at lawrence livermore laboratory. Ann. NY Acad. Sci. 267, 71-80.

Stewart, D. W., Cohen, K., 1940. The further concentration of $\mathrm{S}^{34}$. J. Chem. Phys. 8, 904-907.

Tiemann, E., Knöckel, H., Schlembach, J., 1982. Influence of the finite size on the electronic and rotational energy of diatomic molecules. Ber. Bunsenges. Phys. Chem. $86,821-824$.

Thiemens, M. H., 2006. History and application of mass-independent isotope effects. Annu. Rev. Earth Planet Sci. 34, 217-262.

Turro, N. J., 1983. Influence of nuclear spin on chemical reactions: Magnetic isotope and magnetic field effects (A review). Proc. Natl. Acad. Sci. USA 80, 609-621.

Urey, H. C., Huffman, J. R., Thode, H. G., Fox, M., 1937. Concentration of $\mathrm{N}^{15}$ by chemical methods. J. Chem. Phys. 5, 856-868.

Urey, H. C., 1947. The thermodynamic properties of isotopic substances. J. Chem. Soc. 562-581.

Wakasa, M., Hayashi H., Kobayashi T., Takada, T., 1993. Enrichment of germanium-73 with the magnetic isotope effect. J. Phys. Chem. 97, 13444-13446.

Wakasa M., Hayashi H., Ohara, K., Takada, T., 1998. Enrichment of germanium-73 with the magnetic isotope effect on the hydrogen abstraction reaction of triplet benzophenone with triethylgermane in an SDS miceller solution. J. Am. Chem. Soc. $120,3227-3230$.

Watanabe, Y., Ohmoto, H., 2007. Mass independent fractionation of sulfur isotopes during thermochemical sulfate reduction: Implications to the biosphere evolution. Astrobiology 7, 533-533.

Watanabe, Y., Farquhar, J., Ohmoto, H., 2009. Anomalous fractionations of sulfur isotopes during thermochemical sulfate reduction. Science 324, 370-373. 
1064 Weston, Jr., R. E., 1999, Anomalous or mass-independent isotope effects. Chem. Rev. $106599,2115-2136$.

1066 Yin, Q-Z., Jacobsen, B., Moynier, F., Hutcheon, I. D., 2007. Toward consistent 1067 chronology in the early solar system: High-resolution ${ }^{53} \mathrm{Mn}-{ }^{53} \mathrm{Cr}$ chronometry for 1068 chondrules. Astrophys. J. 662, L43-L46.

1069 Zhang, Y. -H., Gunji, S., Nomura, M., Fujii, Y., Oi, T., 2005. Observation of cerium 1070 isotope fractionation in ion-exchange chromatography of $\mathrm{Ce}(\mathrm{III})$-malate complex.

1071 Zhang, Y. -H., Fukuda, Y., Nomura, M., Fujii, Y., Oi, T., 2006. Zinc isotope effects 1072 1073 observed by liquid chromatography with benzo-15-crown-5-resin. J. Nucl. Sci. Technol. 43, 415-418.

1074

1075

1076 
Table 1 Mass-independent isotope fractionations found in laboratory-scale chemical exchange

1078 experiments which suggest the nuclear field shift effect.

\begin{tabular}{|c|c|c|c|c|}
\hline & Reaction & Method & Isotopic analysis & Reference \\
\hline \multirow[t]{3}{*}{$\mathrm{Ca}$} & Ligand exchange & Liquid chromatography & TIMS & Heumann et al., 1982 \\
\hline & Ligand exchange & Liquid membrane & TIMS & Fujii et al., 1985 \\
\hline & Ligand exchange & Liquid chromatography & TIMS & Oi et al., 1993 \\
\hline $\mathrm{Ti}$ & Ligand exchange & Solvent extraction & MC-TIMS & Fujii et al., 1998a \\
\hline \multirow{6}{*}{$\mathrm{Cr}$} & Ligand exchange & Solvent extraction & TIMS & Kawashiro et al., 1998 \\
\hline & Ligand exchange & Solvent extraction & MC-TIMS & Fujii et al., 2002 \\
\hline & Ligand exchange & Solvent extraction & MC-ICP-MS & Fujii et al., 2007 \\
\hline & Redox & Pyrometallurgical extraction & MC-ICP-MS & Fujii et al., 2007 \\
\hline & Ligand exchange & Solvent extraction & MC-ICP-MS & Fujii et al., 2008a \\
\hline & Ligand exchange & Repeated extraction & MC-TIMS & Fujii et al., 2008b \\
\hline $\mathrm{Ni}$ & Ligand exchange & Solvent extraction & TIMS & Nishizawa et al., 1997 \\
\hline \multirow[t]{6}{*}{$\mathrm{Zn}$} & Ligand exchange & Solvent extraction & ICP-QMS & Nishizawa et al., 1993 \\
\hline & Ligand exchange & Solvent extraction & TIMS & Nishizawa et al., 1996 \\
\hline & Ligand exchange & Liquid membrane & TIMS & Nishizawa et al., 1998a \\
\hline & Ligand exchange & Liquid chromatography & MC-ICP-MS & Nishizawa et al., 1998b \\
\hline & Ligand exchange & Liquid chromatography & MC-ICP-MS & Fujii et al., 2001a \\
\hline & Ligand exchange & Liquid chromatography & ICP-QMS & Zhang et al., 2006 \\
\hline \multirow[t]{7}{*}{$\mathrm{Sr}$} & Ligand exchange & Solvent extraction & TIMS & Nishizawa et al., 1994 \\
\hline & Ligand exchange & Solvent extraction & TIMS & Nishizawa et al., 1995 \\
\hline & Ligand exchange & Liquid chromatography & TIMS & Ban et al., 2001 \\
\hline & Ligand exchange & Liquid chromatography & ICP-QMS & Shibahara et al., 2002b \\
\hline & Ligand exchange & Solvent extraction & TIMS & Shibahara et al., 2002c \\
\hline & Ligand exchange & Liquid chromatography & ICP-QMS & Shibahara et al., 2003 \\
\hline & Ligand exchange & Liquid chromatography & ICP-QMS & Shibahara et al., 2006 \\
\hline Mo & Ligand exchange & Solvent extraction & MC-ICP-MS & Fujii et al., 2006c \\
\hline $\mathrm{Ru}$ & Ligand exchange & Solvent extraction & MC-ICP-MS & Fujii et al., 2006c \\
\hline $\mathrm{Te}$ & Ligand exchange & Solvent extraction & MC-ICP-MS & Moynier et al., 2008 \\
\hline \multirow[t]{5}{*}{$\mathrm{Ba}$} & Ligand exchange & Solvent extraction & TIMS & Nishizawa et al., 1994 \\
\hline & Ligand exchange & Liquid chromatography & TIMS & Kondoh et al., 1996 \\
\hline & Redox & Electrolytic reduction & TIMS & Chang et al, 1996 \\
\hline & Ligand exchange & Solvent extraction & TIMS & Shibahara et al., 2002a \\
\hline & Ligand exchange & Liquid chromatography & TIMS & Ban., 2002 \\
\hline $\mathrm{Nd}$ & Ligand exchange & Solvent extraction & MC-TIMS & Fujii et al., 2000 \\
\hline
\end{tabular}




\begin{tabular}{|l|l|l|l|l|}
\hline Sm & Ligand exchange & Solvent extraction & MC-TIMS & Fujii et al., 1998c \\
\hline & Redox & Electrolytic reduction & MC-TIMS & Dembiński et al, 2001 \\
\hline Gd & Ligand exchange & Liquid chromatography & TIMS & Chen et al., 1992 \\
\hline & Ligand exchange & Solvent extraction & MC-TIMS & Fujii et al., 1999 \\
\hline & Ligand exchange & Liquid chromatography & TIMS & Ismail et al., 2000 \\
\hline Yb & Redox & Reduction extraction & MC-TIMS & Dembiński et al, 1998 \\
\hline & Redox & Reduction extraction & MC-TIMS & Dembiński et al, 2001 \\
\hline U & Redox & Liquid chromatography & TIMS & Fujii et al., 1989a,b \\
\hline
\end{tabular}

ICP-QMS: Inductively coupled plasma quadrupole mass spectrometry

1081 MC-TIMS: Multicollector thermal ionization mass spectrometry

1082 MC-ICP-MS: Multicollector inductively coupled plasma mass spectrometry 
1084 Figure captions

1085 Figure 1 Vibrational potential curves of isotopologues.

1086 Figure 2 Electrostatic potentials of nuclei. (a) The Coulomb potential for a point nucleus. 1087 (b) The electrostatic potential for a nucleus of the same charge with a finite size of 1088 charge distribution. (c) The electrostatic potential for another nucleus with the same 1089 charge but a larger size of charge distribution.

1090 Figure 3 Hyperfine splitting levels of a ${ }^{235} \mathrm{U}(\mathrm{III})$ complex. The ground state energy is set 1091 to be zero (see Table 2 in (Bigeleisen, 1996a)).

1092 Figure 4 Applicability of the Bigleiesen's (1996) theory to experimental results at a 1093 constant temperature. The nuclear spin of the even isotopes is set to be zero, while odd 1094 isotopes have non-zero spin.

1095 Figure 5 Changes in mean-square nuclear charge radii. Data and errors are from 1096 (Aufmuth, 1987) unless otherwise indicated. Isotopic differences are relative to the most 1097 abundant isotope. a) S (Angeli, 2004), b) Ca, c) Ti (Fricke and Heilig, 2004), d) Cr, e) $1098 \mathrm{Fe}, \mathrm{f}) \mathrm{Ni}$. g) Zn (only relative values of $\delta<r^{2}>$ are available (Aufmuth, 1987)), h) Sr, i) 1099 Zr, j) Mo, k) Ru, l) Te (Fricke and Heilig, 2004), m) Ba, n) Ce, o) Nd, p) Sm, q) Gd, r) $1100 \mathrm{Yb}, \mathrm{s}) \mathrm{Hf}, \mathrm{t}) \mathrm{U}$.

1101 Figure 6 Temperature dependence of isotope fractionation predicted by Bigleiesen's 1102 (1996) theory at various temperatures.

1103 Figure 7 Vibrational potential curves of isotopologues (including transition state) in a 1104 chemical reaction.

1105 Figure 8 Isotope enrichment factors of $\mathrm{Ca}$. (a) Isotope fractionation of $\mathrm{Ca}$ at a distance $x$ 1106 compared to that in original solution (cation exchange membrane system, $298 \mathrm{~K}$ (Fujii 1107 et al., 1985)). (b) Isotope fractionation of Ca between eluent and resin (cation exchange 1108 chromatography, 298K (acetate) (Oi et al., 1993)).

1109 Figure 9 Isotope enrichment factors of $\mathrm{Ti}$. Ti isotopes were fractionated by using a 1110 solvent extraction technique with a crown ether, (organic solution)/(HCl solution) (Fujii 1111 et al., 1998a). Errors are $2 \sigma$ analytical errors. a) Ti(III), b) Ti(IV).

1112 Figure 10 Isotope enrichment factors of $\mathrm{Cr}$. $\mathrm{Cr}$ isotopes were fractionated by using a 1113 solvent extraction technique with a crown ether, (organic solution)/( $\mathrm{HCl}$ solution). 1114 Mass-dependent lines (dotted lines) were drawn for an isotope pair, ${ }^{50} \mathrm{Cr}-{ }^{52} \mathrm{Cr}$. Errors are 
$11152 \sigma$ analytical errors. a) isotope fractionation of $\mathrm{Cr}$ in organic phase compared to that in 1116 an original solution (Fujii et al., 2007). The isotope enrichment factor for ${ }^{54} \mathrm{Cr}$ was an 1117 estimated value (Fujii et al., 2007, 2008a). b) isotope fractionation of $\mathrm{Cr}$ in aqueous 1118 phase compared to that in an original solution (Fujii et al., 2008b).

1119 Figure 11 Isotope enrichment factors of Fe. Fe isotopes were fractionated by using a 1120 solvent extraction technique with a crown ether, (organic solution)/(HCl solution). In 1121 the extraction reaction, only a very small deviation from the mass-dependent property 1122 was observed. The reported $\varepsilon(\mathrm{L})$ data (Fujii et al, 2006b) are plotted showing $2 \sigma$ 1123 analytical errors. A mass-dependent line (dotted line) is shown for the isotope pair, 1124 ${ }^{54} \mathrm{Fe}-{ }^{56} \mathrm{Fe}$. The isotope enrichment factor for ${ }^{58} \mathrm{Fe}$ was estimated by using Eq. 31.

1125 Figure 12 Isotope enrichment factors of $\mathrm{Zn}$. $\mathrm{Zn}$ isotopes were fractionated by liquid 1126 chromatography (Nishizawa et al., 1998b). A cryptand polymer was used as the 1127 stationary phase, and the liquid phase was a mixture of water-acetone-hydrochloric acid. 1128 Isotope fractionation of $\mathrm{Zn}$ between eluent (sample number 12) and resin was shown. 1129 The error bars are smaller than the data symbols.

1130 Figure 13 Isotope enrichment factors and changes in mean-square radius in Sr. Open 1131 marks showed the result of Nishizawa et al. (1995) (isotope fractionation of Sr between 1132 organic phase and aqueous phase). The analytical errors of isotope ratio are reported to 1133 be less than $0.1 \%(1 \sigma)$. The $\delta<r^{2}>$ values and their errors are reproduced from (Aufmuth 1134 et al., 1987).

1135 Figure 14 Isotope enrichment factors of Mo. Mo isotopes were fractionated using a 1136 solvent extraction technique with a crown ether, (organic solution)/(HCl solution). 1137 Enrichment factors obtained at 5.4 M HCl (Fujii et al. 2006c) are shown. $2 \sigma$ analytical 1138 errors are also shown (detailed error evaluation method can be seen in (Fujii et al. 1139 2006c)).

1140 Figure 15 Dependence of nuclear field shift effect and mass-dependent fractionation of 1141 Mo and $\mathrm{Ru}$. Relative contributions of nuclear field shift effect and mass-dependent 1142 fractionation to isotope enrichment factors of the isotope pairs ${ }^{100}{ }^{\mathrm{Mo}-}{ }^{95} \mathrm{Mo}$ and $1143{ }^{104}{ }^{\mathrm{Ru}}-{ }^{-99} \mathrm{Ru}$ were evaluated with Eq. 31 in this article.

1144 Figure 16 Isotope enrichment factors for $\mathrm{Ru}$. $\mathrm{Ru}$ isotopes were fractionated using a 1145 solvent extraction technique with a crown ether, (organic solution)/(HCl solution). 1146 Enrichment factors obtained at 8.2 $\mathrm{M} \mathrm{HCl}$ (Fujii et al. 2006c) are shown. The error bars 1147 are smaller than the data symbols. (details of the error evaluation method are in (Fujii et 
1148

1149

1150

1151

1152

1153

1154

1155

1156

1157

1158

1159

1160

1161

1162

1163

1164

1165

1166

1167

1168

1169

1170

1171

1172

1173

1174

1175

1176

1177

1178

1179

1180

al. 2006c)).

Figure 17 Isotope enrichment factors for Te. Te isotopes were fractionated using a solvent extraction technique with a crown ether, (organic solution)/( $\mathrm{HCl}$ solution). The enrichment factors obtained at 5.62 M HCl (Moynier et al. 2008) are shown. Errors are $2 \sigma$ analytical errors. ${ }^{120} \mathrm{Te}$ and ${ }^{123} \mathrm{Te}$ are not shown.

Figure 18 Changes in mean-square charge radius and reported isotope enrichment factors for Ba. (a) $\delta<r^{2}>$ : Reproduced from Fig. 5(m). (b) $\varepsilon$ values found in liquid-liquid extraction (Nishizawa et al., 1994). $2 \sigma$ errors are shown. (c) $\varepsilon$ values found in cation exchange chromatography with barium acetate (Kondoh et al., 1996). Analytical errors are not shown. (d) $\varepsilon$ values found in an amalgam/aqueous solution system (Chang et al., 1996). Errors are $2 \sigma$. (e) $\varepsilon$ values found in a liquid-liquid extraction system (Shibahara et al., 2002a). Errors are $2 \sigma$. (f) $\varepsilon$ values found in ligand exchange chromatography with a crown ether (Run B-1) (Ban, 2002). Errors are $2 \sigma$.

Figure 19 Isotope enrichment factors for $\mathrm{Ce}$ in liquid chromatography. Isotope fractionation was measured between $\mathrm{Ce}(\mathrm{III})$-malate and Ce ions on a cation-exchange resin (Zhang et al., 2005).

Figure 20 Isotope enrichment factors for $\mathrm{Sm}$. a) Sm isotopes were fractionated using solvent extraction with a crown ether, (organic solution)/( $\mathrm{HCl}$ solution). Enrichment factors at $1 \mathrm{M} \mathrm{HCl}$ (Fujii et al., 1998c) are shown. Errors are $2 \sigma .{ }^{144} \mathrm{Sm}$ was not used for discussion. b) Isotope fractionation of $\mathrm{Sm}$ in a ( $\mathrm{Sm}$ (III) acetate/Sm in amalgam) was studied (Dembiński et al., 2001). $2 \sigma$ analytical errors are shown.

Figure 21 Isotope enrichment factors for Gd. a) Gd isotopes were fractionated using solvent extraction with a crown ether, (organic solution)/( $\mathrm{HCl}$ solution). Enrichment factors obtained at $2 \mathrm{M} \mathrm{HCl}$ (Fujii et al., 1999) are shown. Errors are $2 \sigma .{ }^{155} \mathrm{Gd}$ and ${ }^{157} \mathrm{Gd}$ were not used for discussion. b) Gd isotopes were fractionated in liquid chromatography. Isotope fractionation was measured between $\mathrm{Gd}(\mathrm{III})$-EDTA and $\mathrm{Gd}$ ions on a cation-exchange resin (Ismail et al., 2000). Errors are $2 \sigma$.

Figure 22 Isotope enrichment factors for U. U isotopes were fractionated in liquid chromatography. Isotope fractionation in an U(IV)-U(VI) reaction was studied ((Fujii et al., 1989a,b)). The error bars are smaller than the data symbols. Isotope enrichment factors are referred in (Bigeleisen, 1996a). 


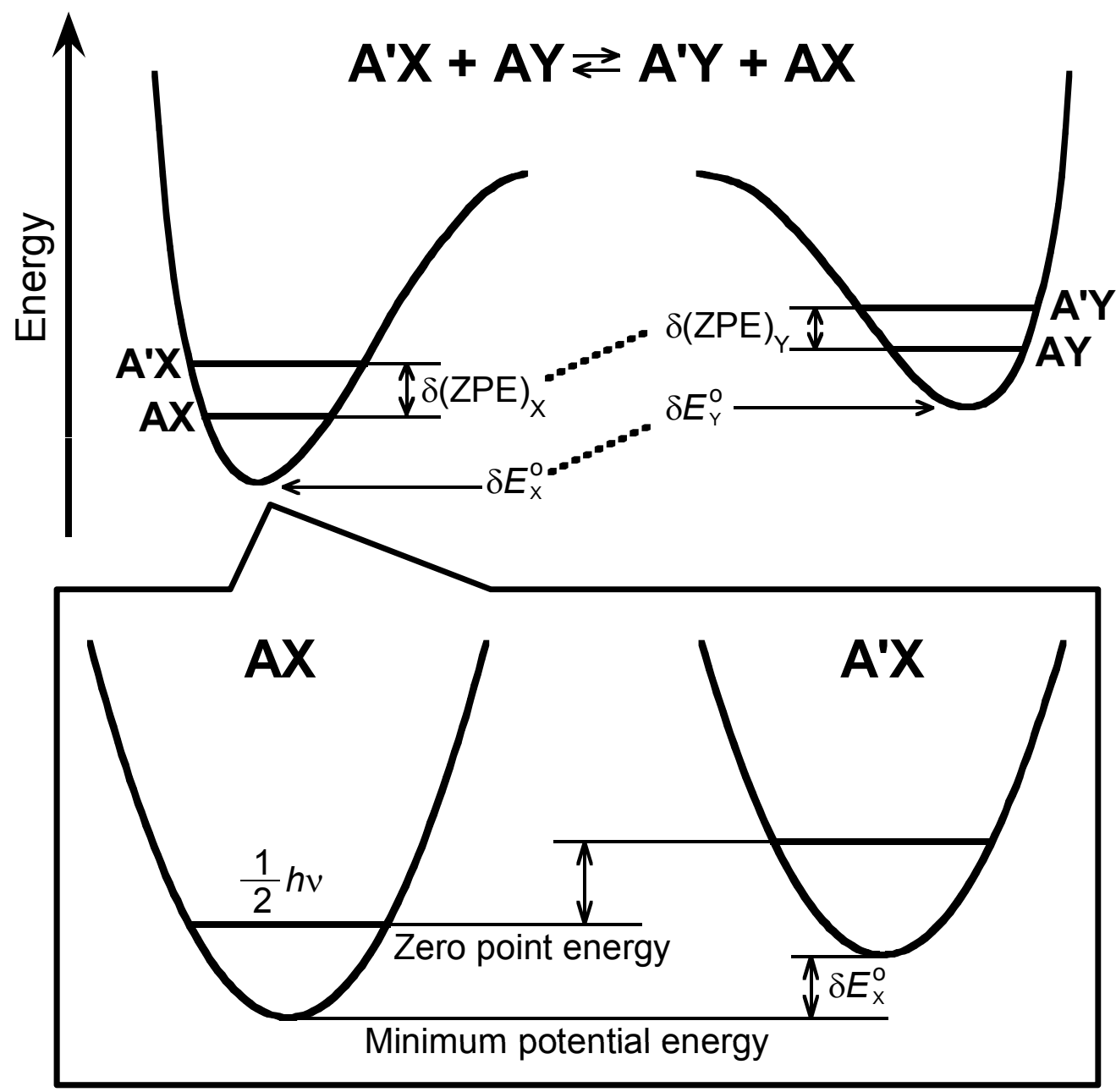




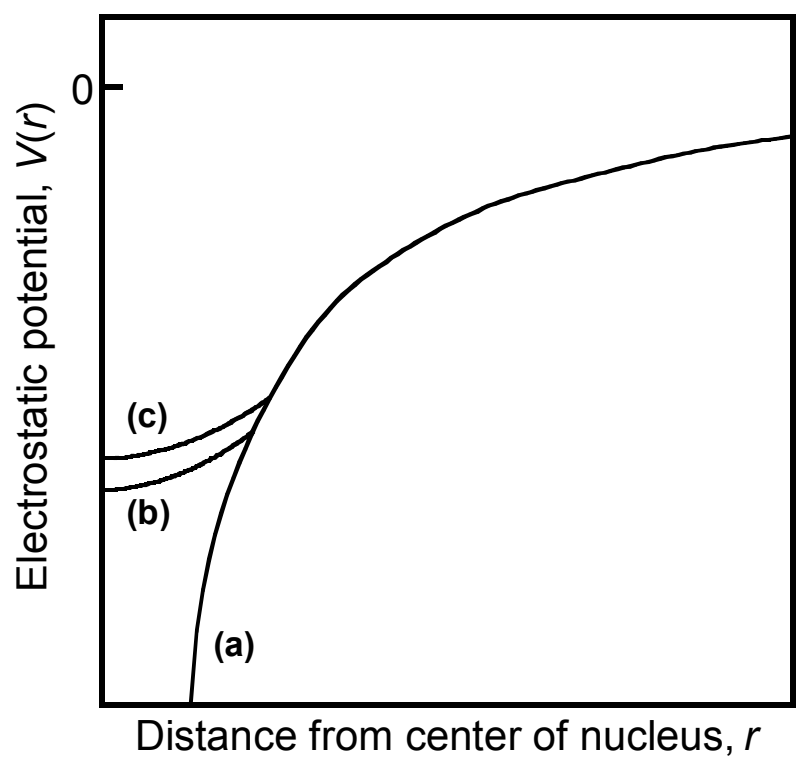




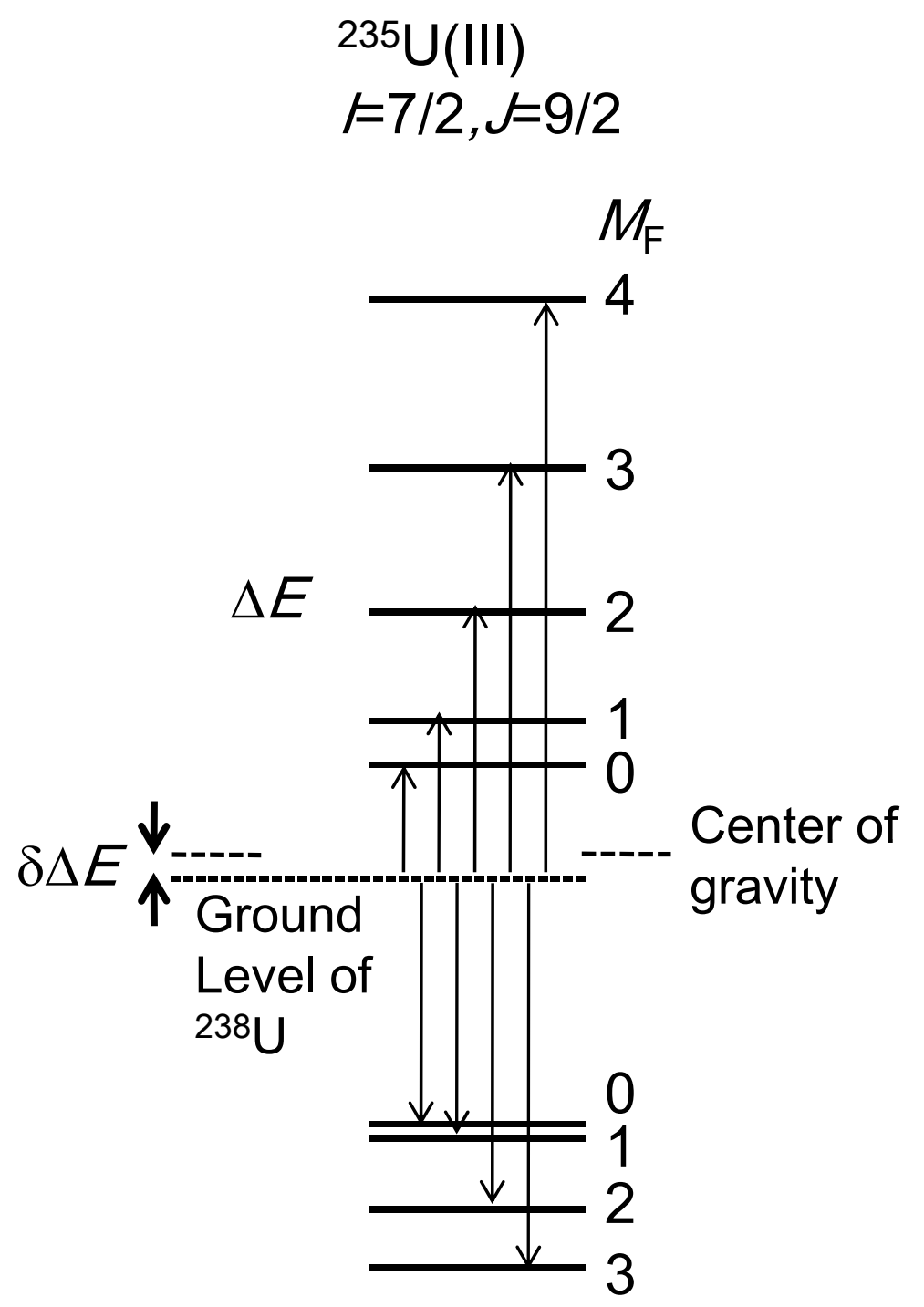




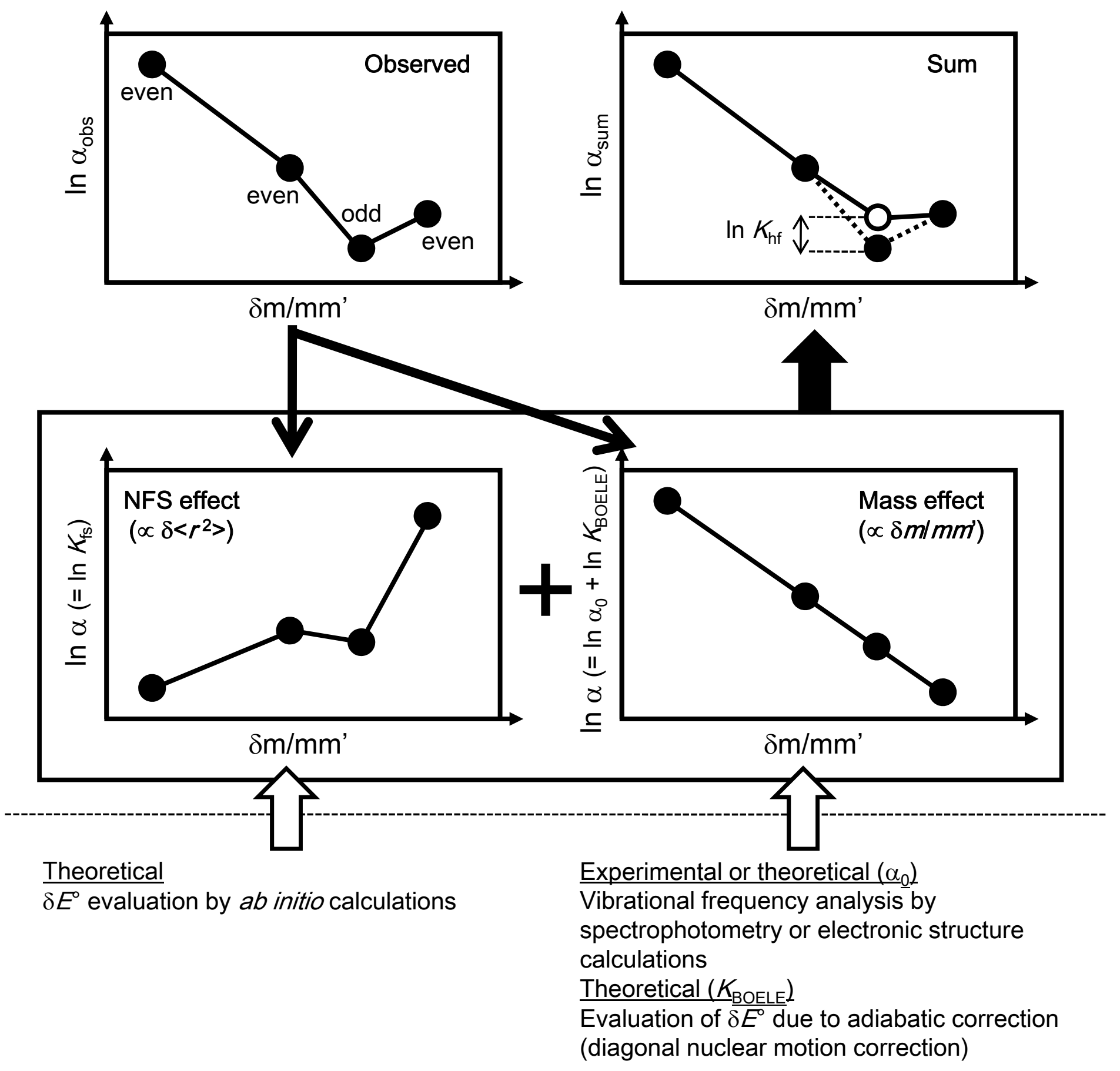



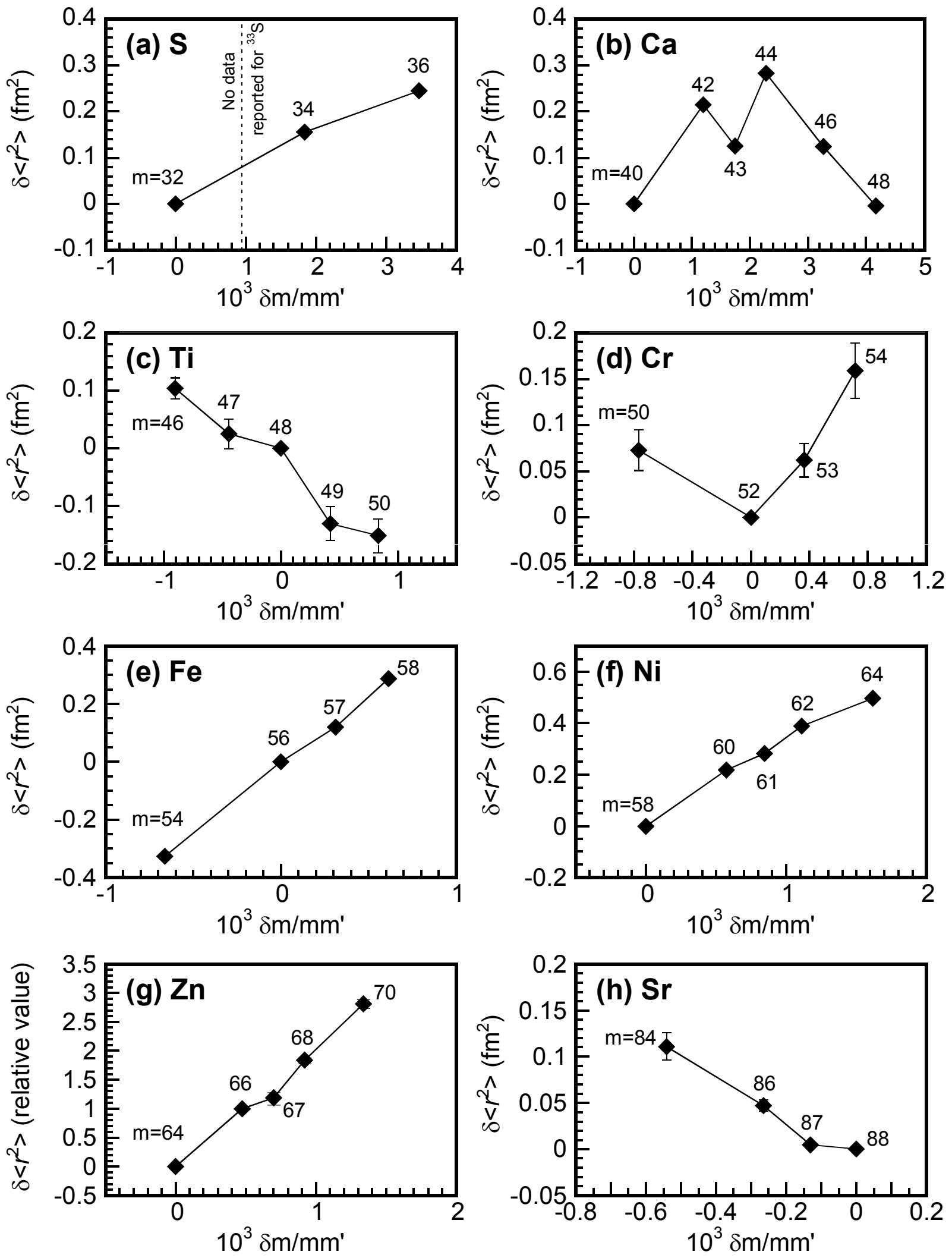

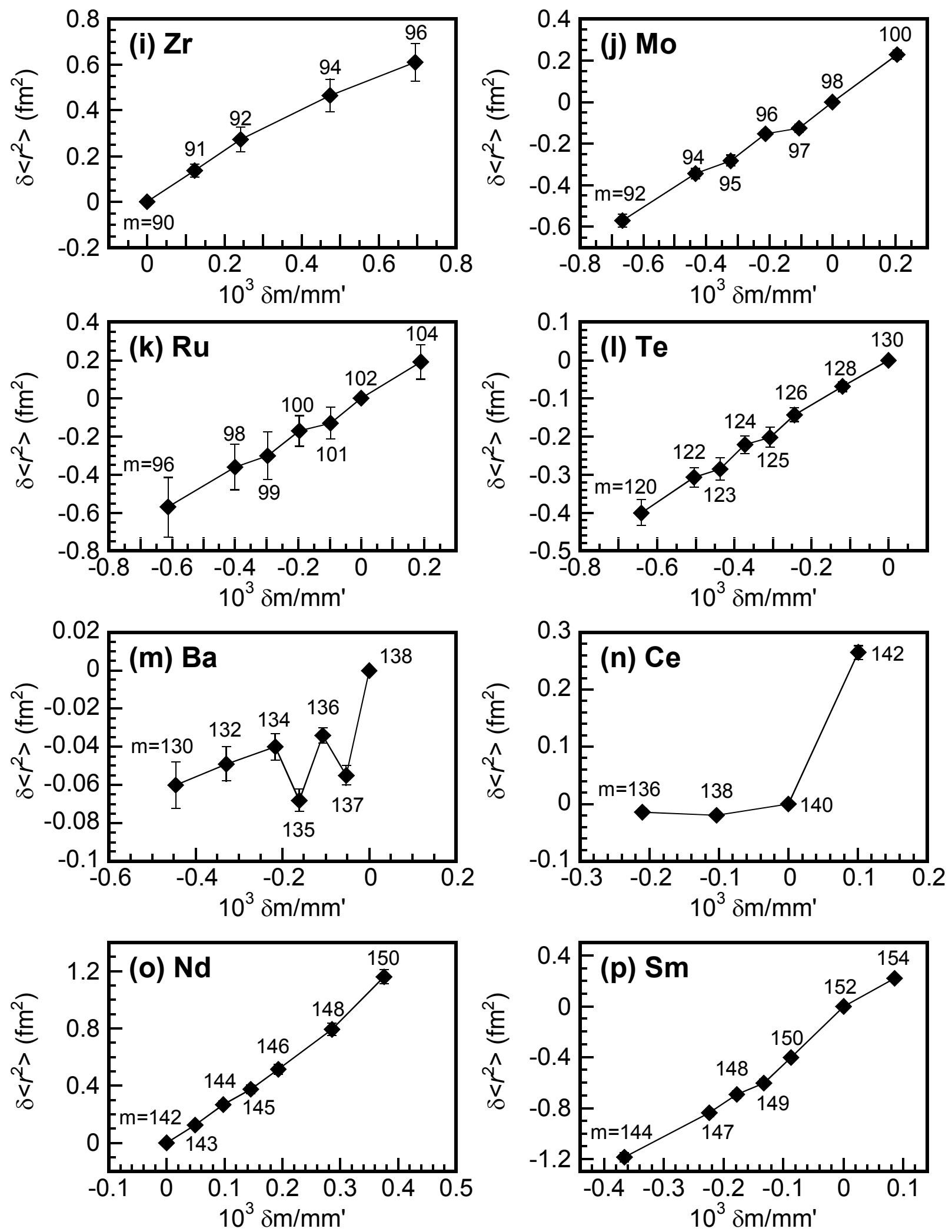

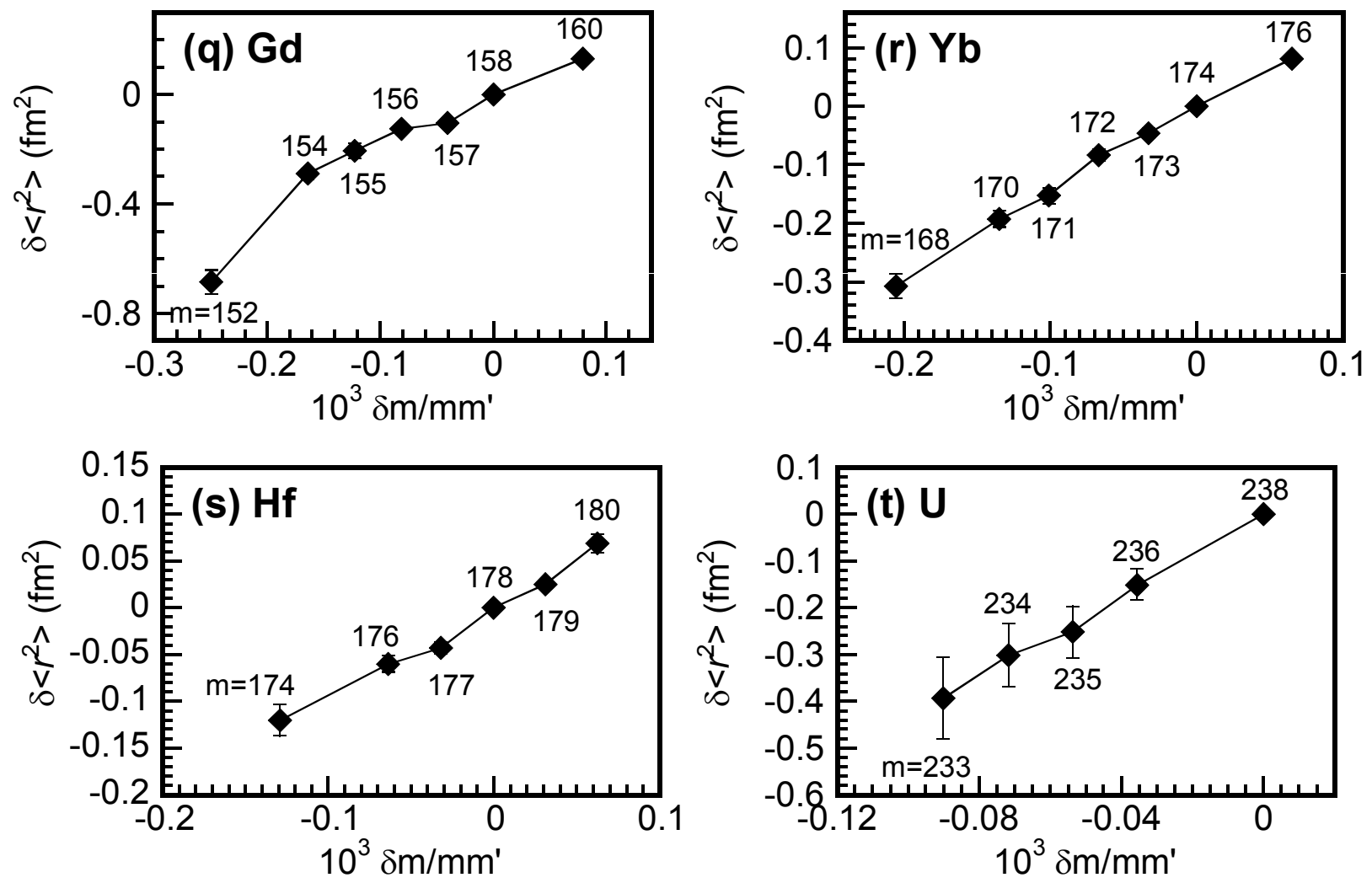


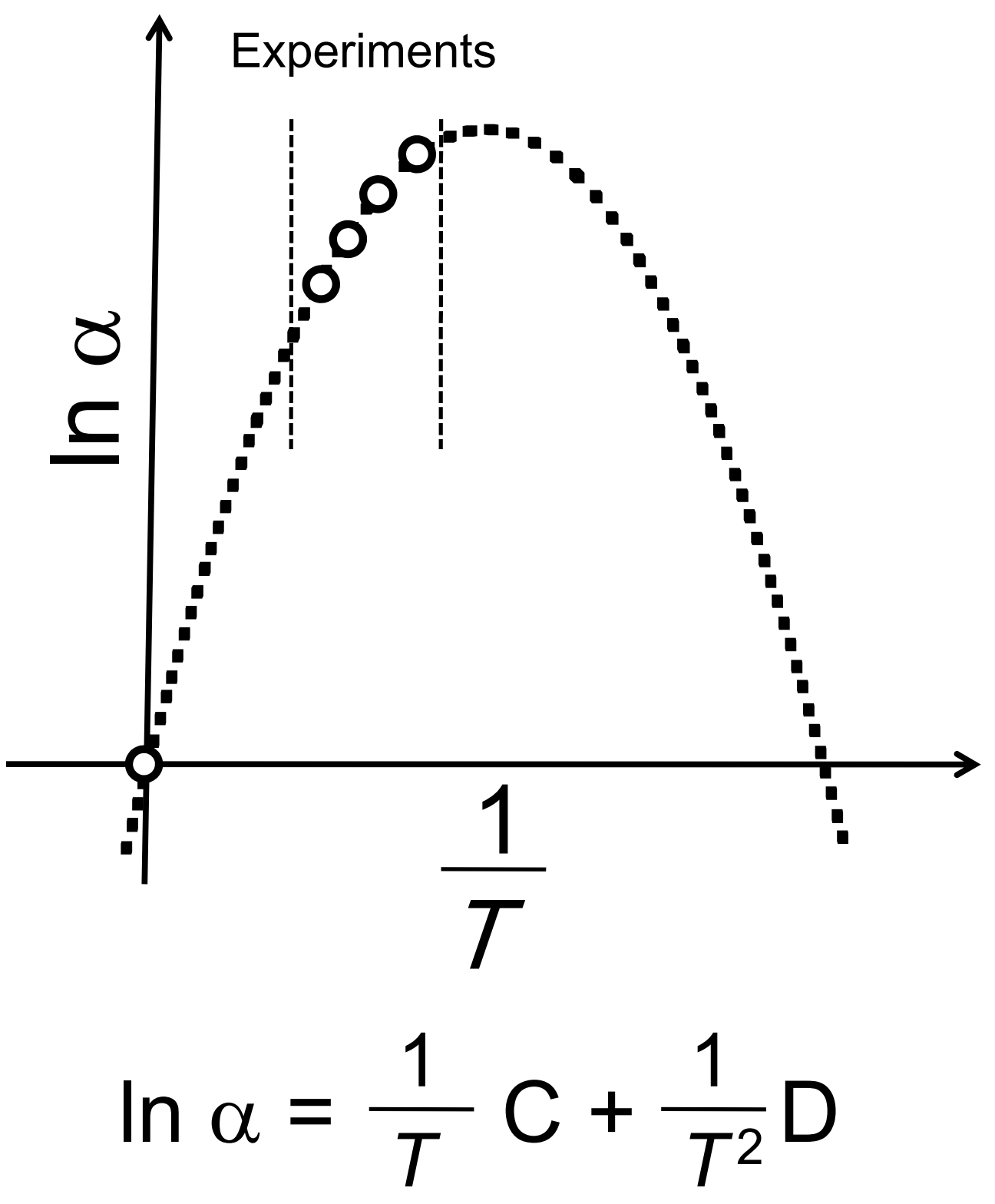




$$
A X+Y \gtrless(A X Y)^{\neq} \rightarrow A Y+X
$$

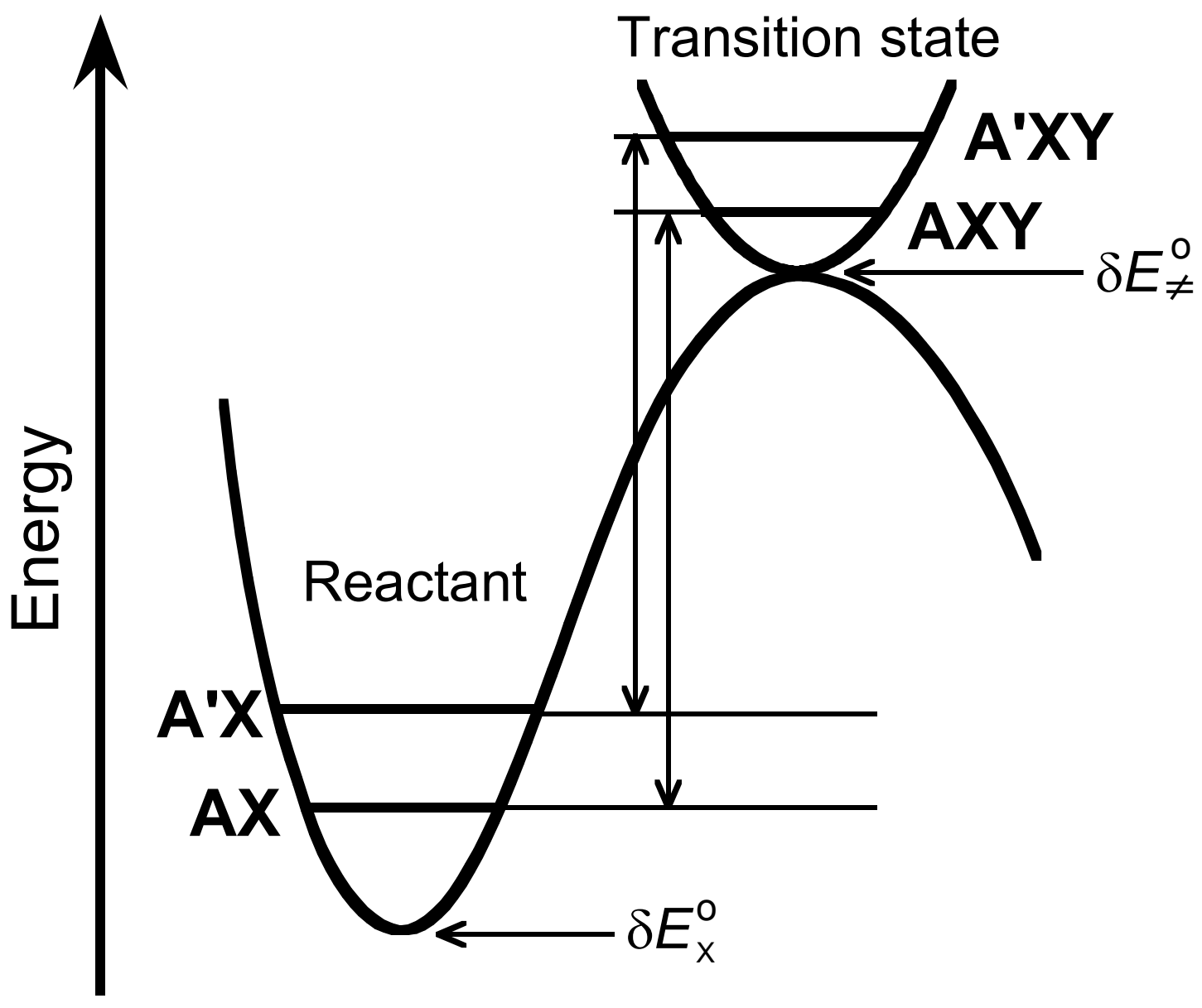



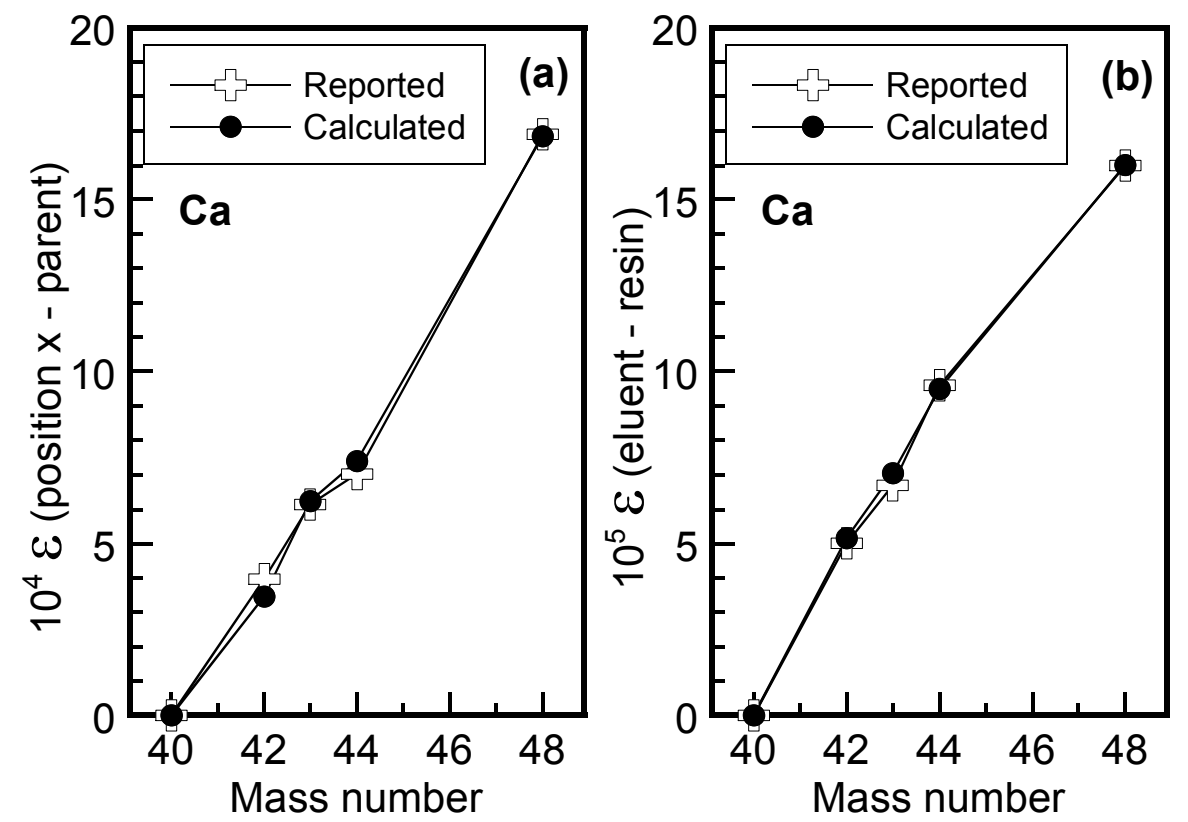

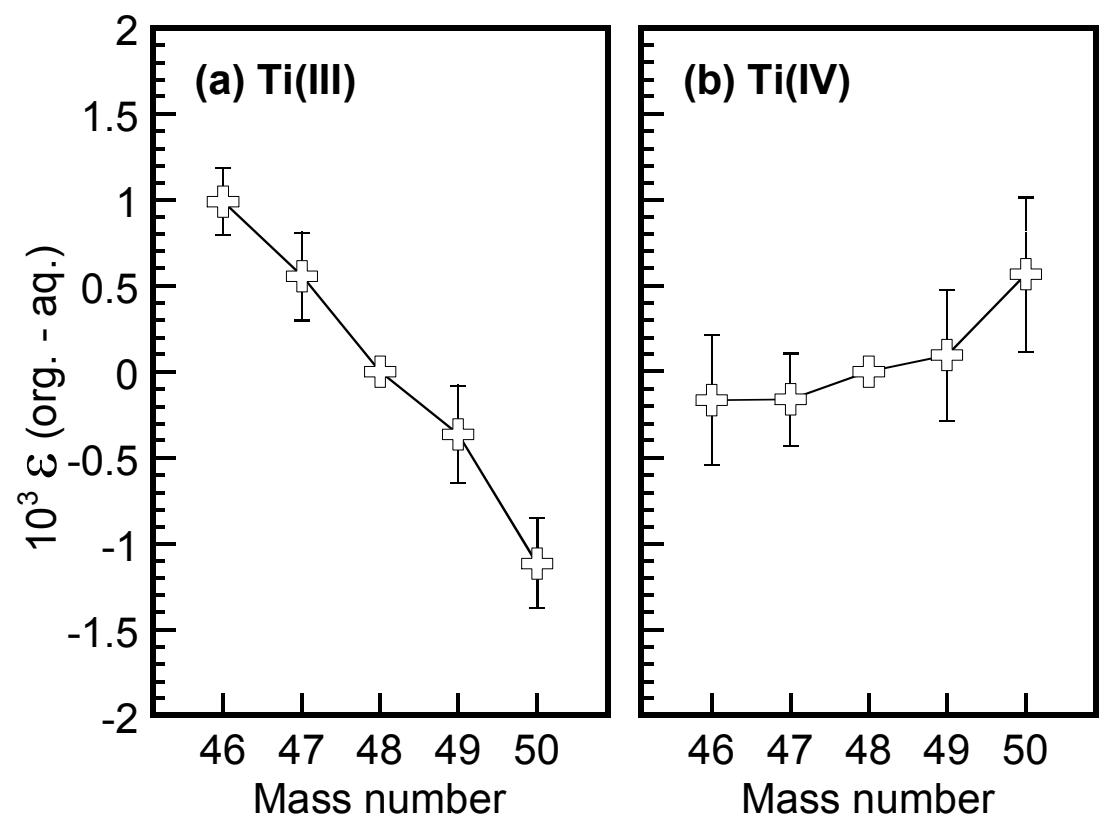


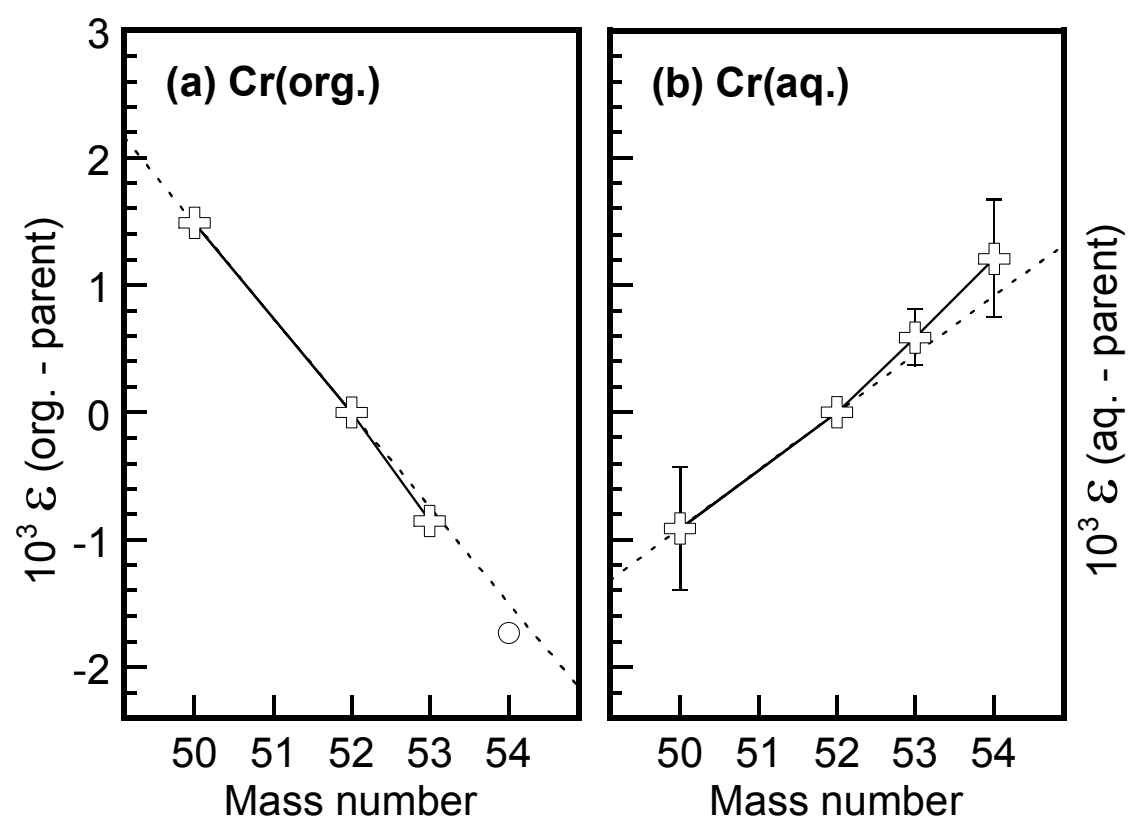




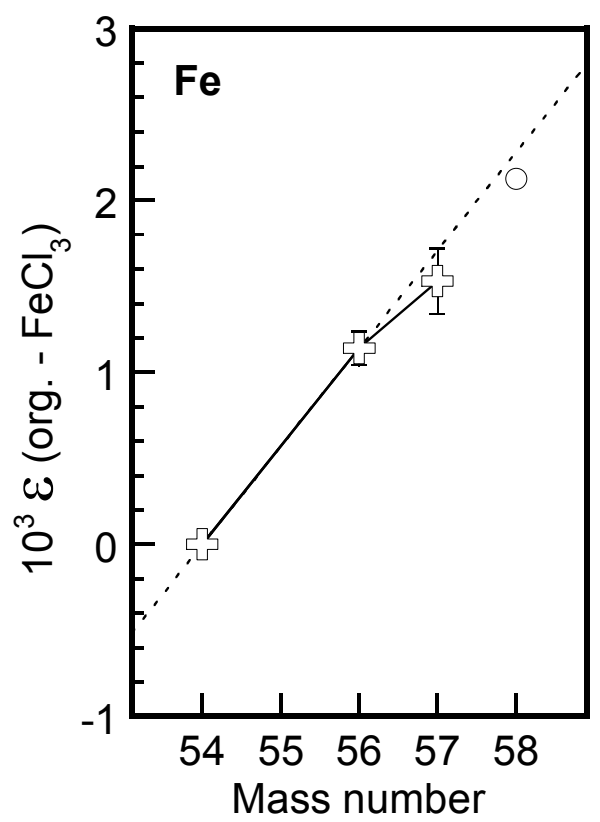




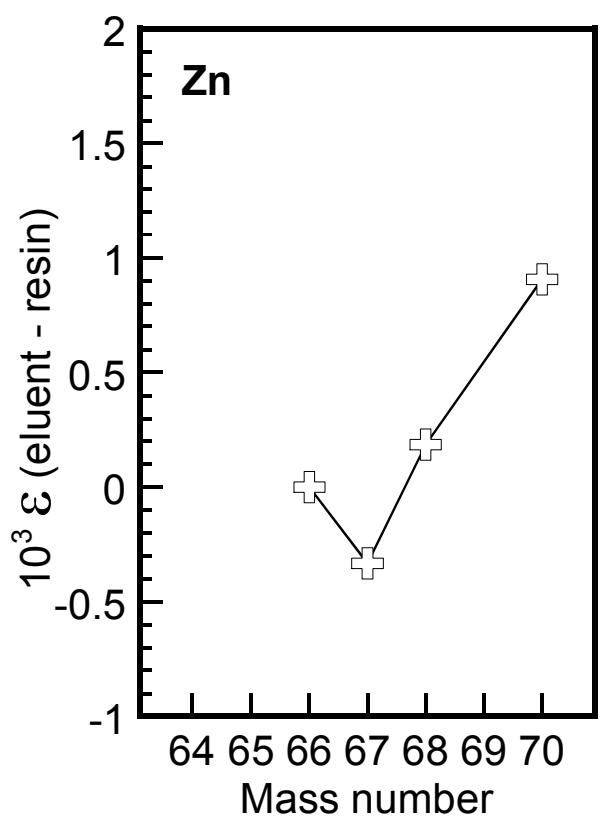




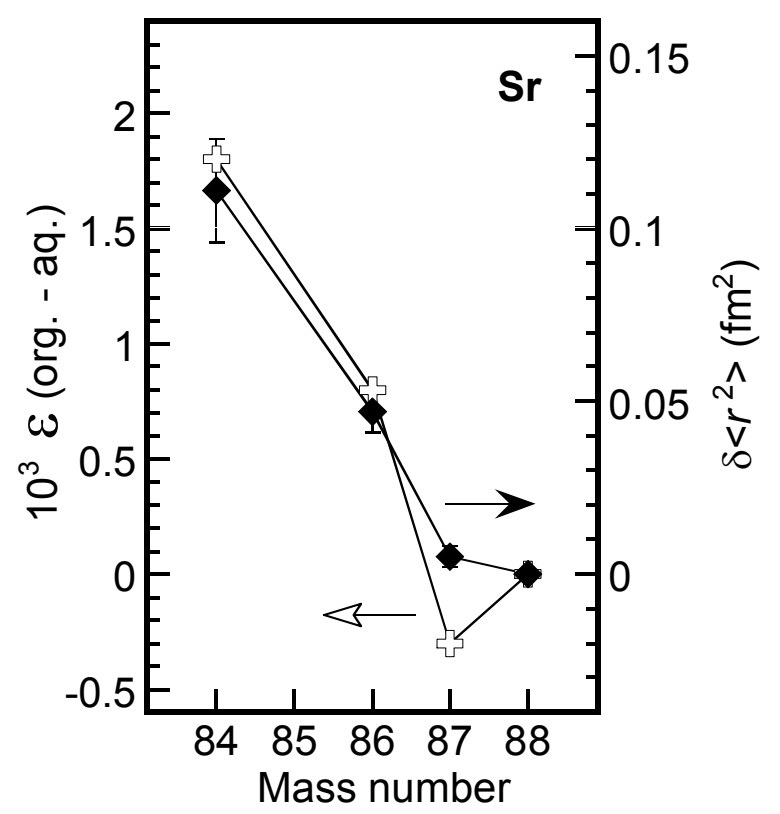




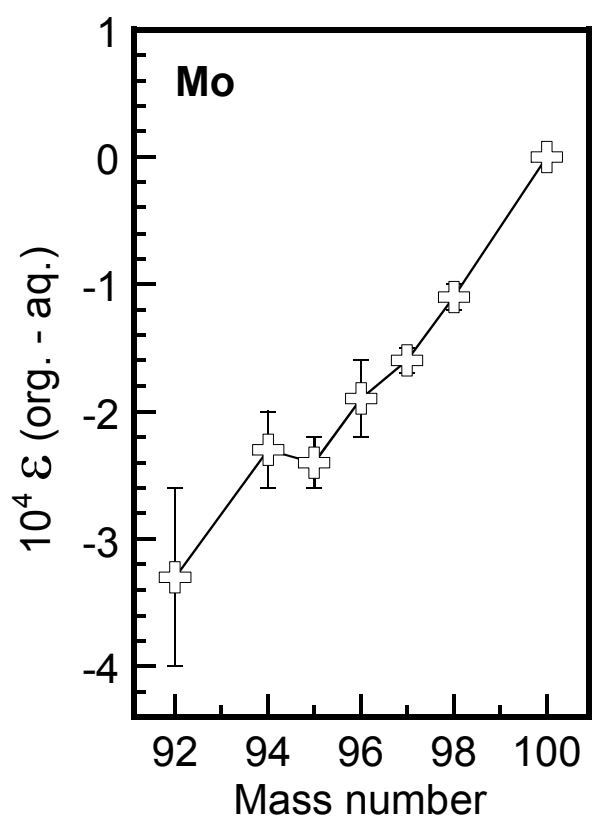




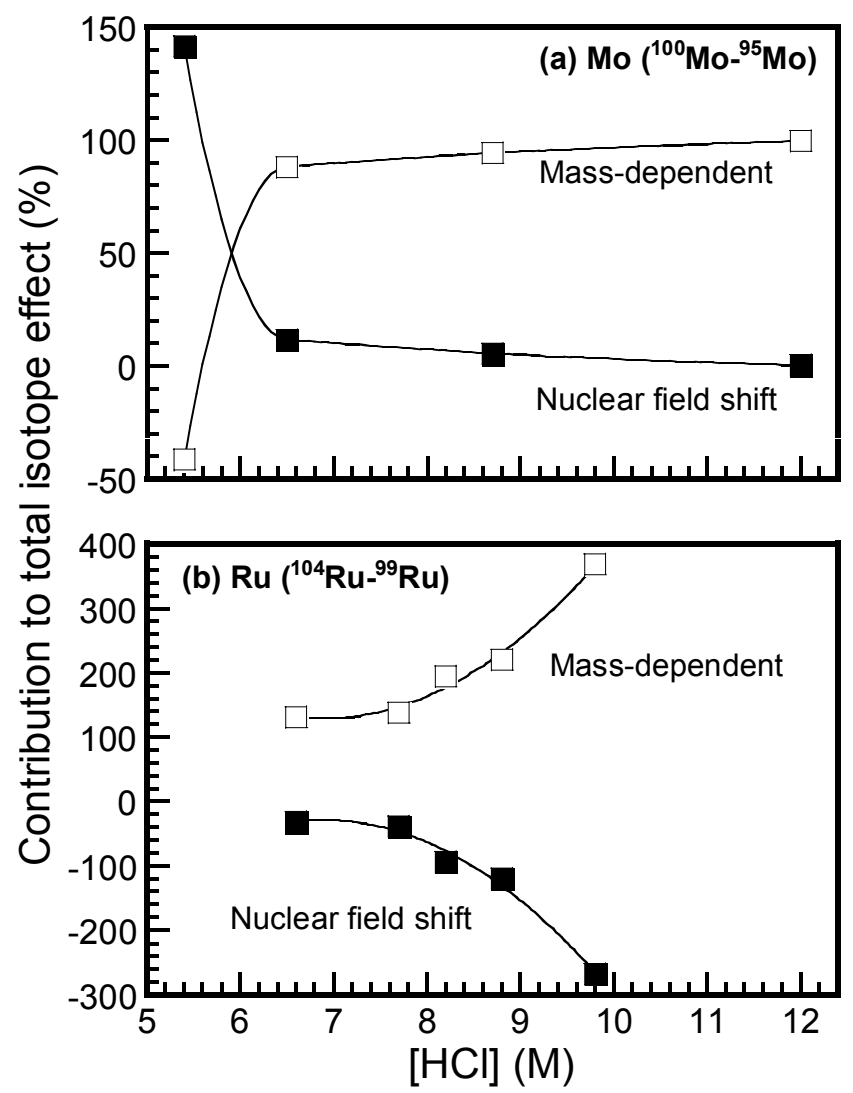




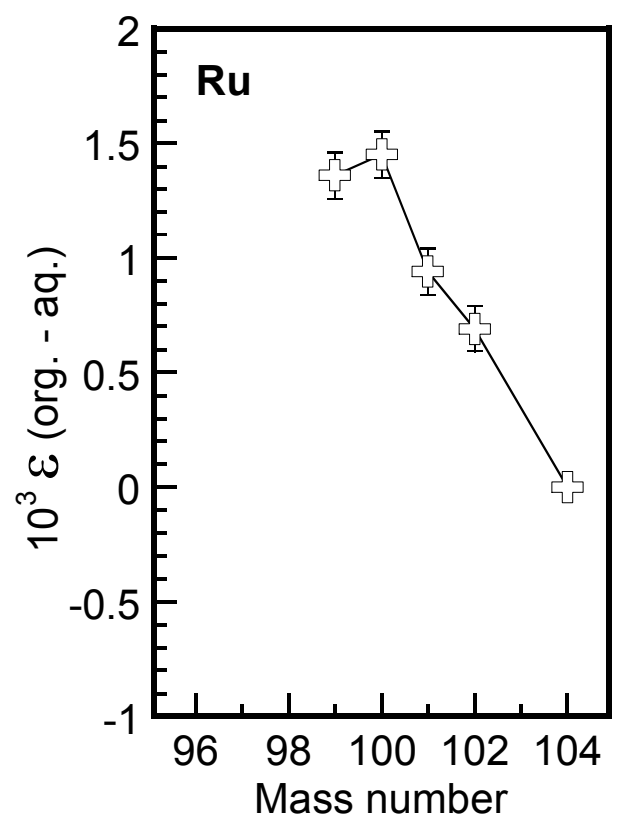




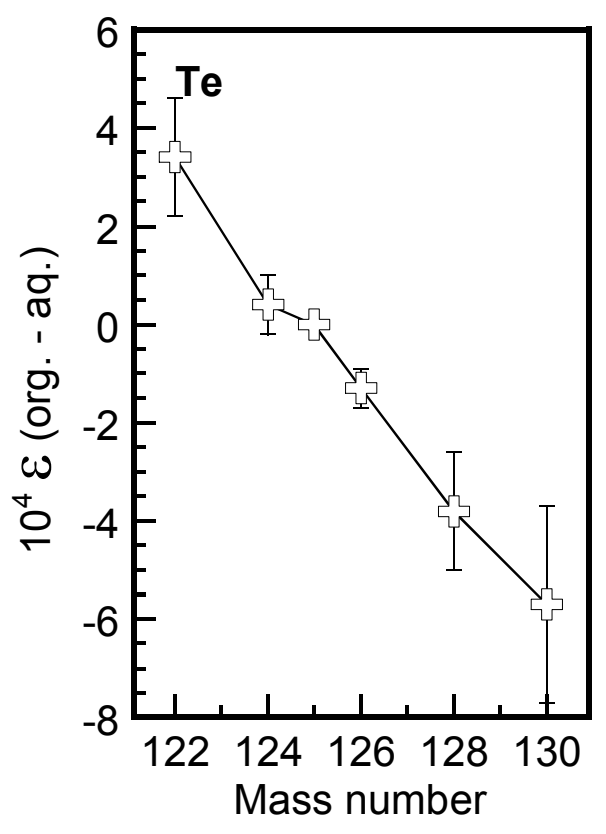



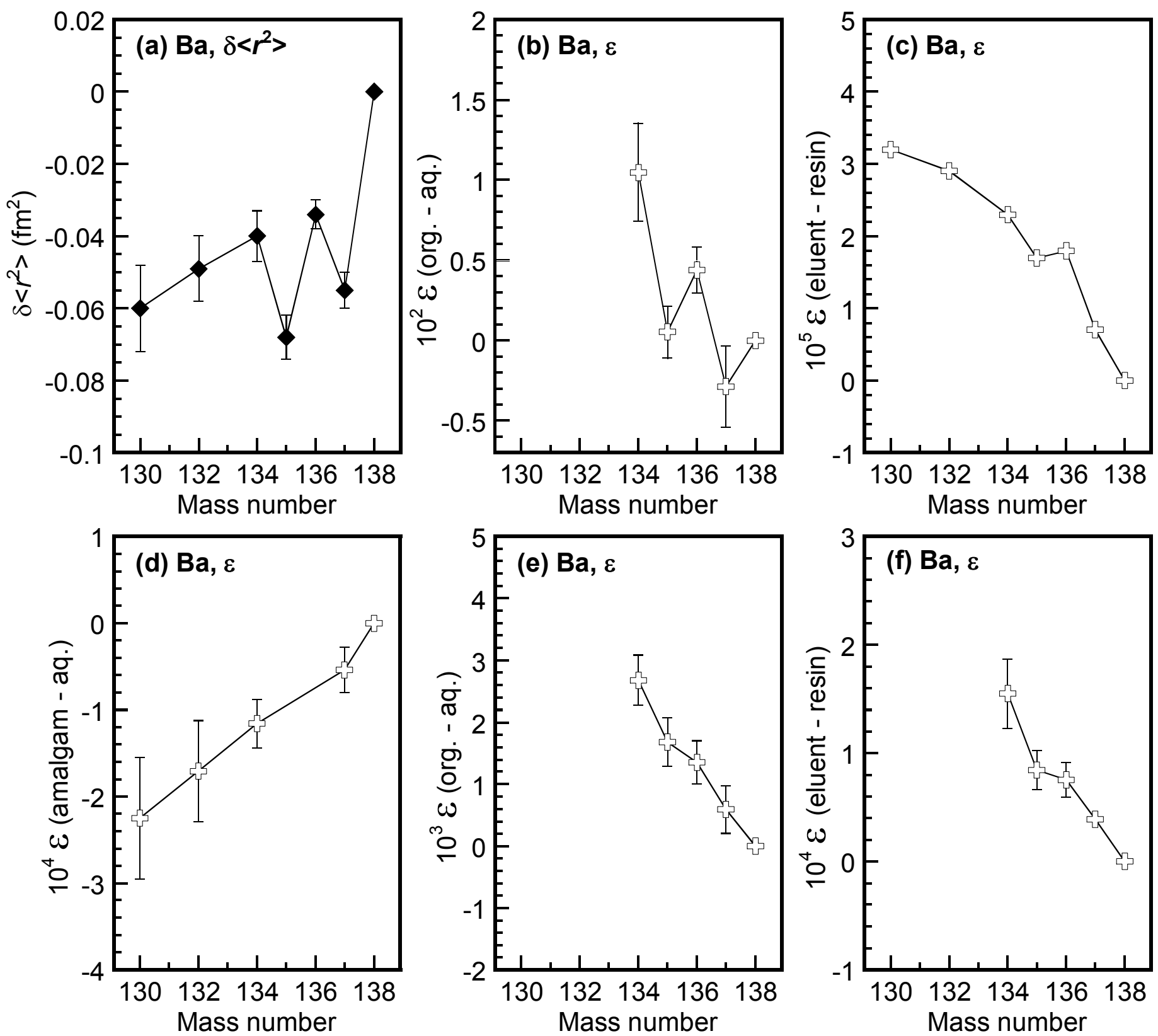


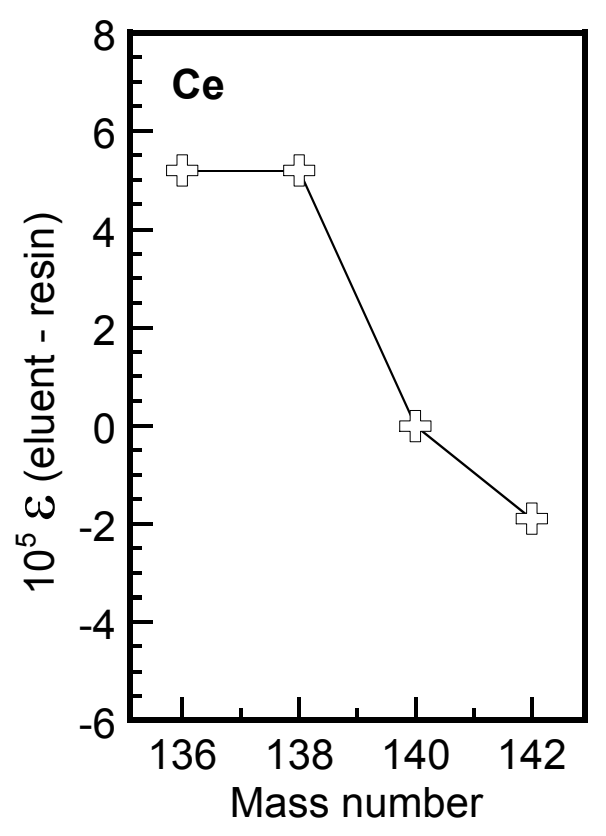



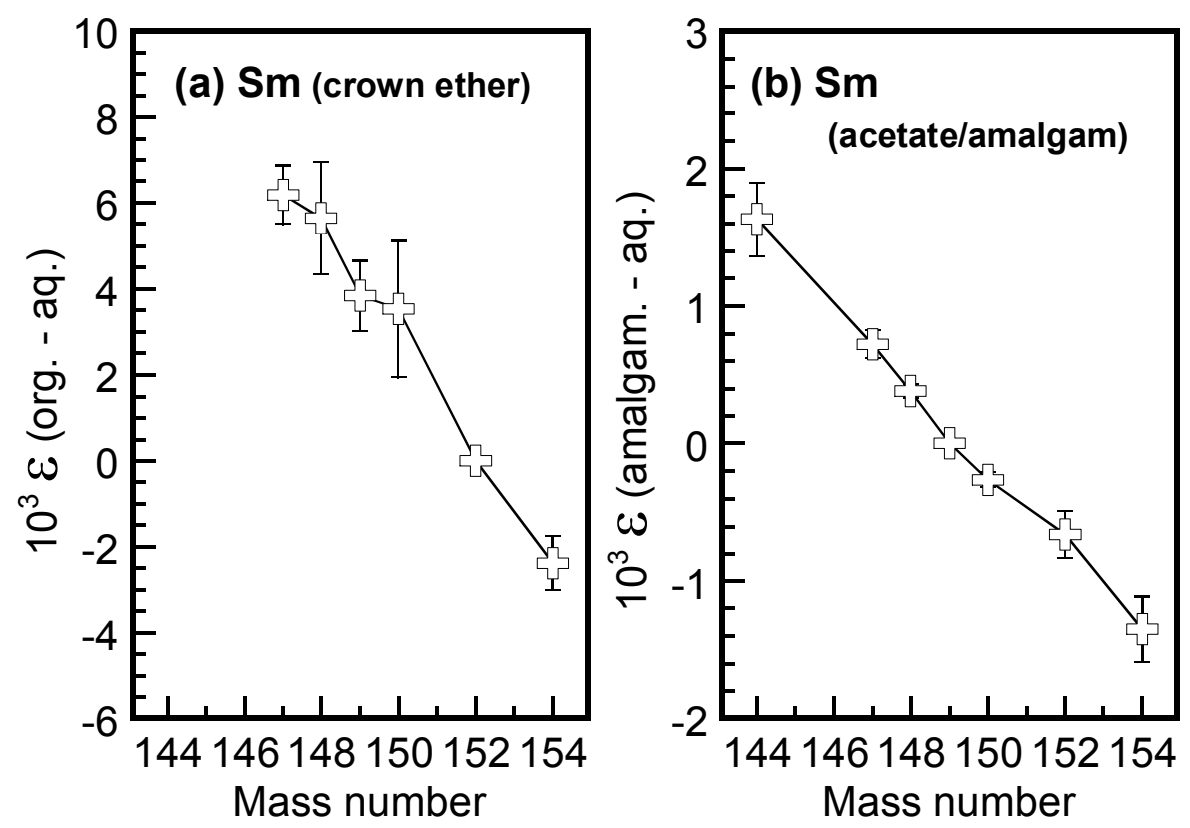

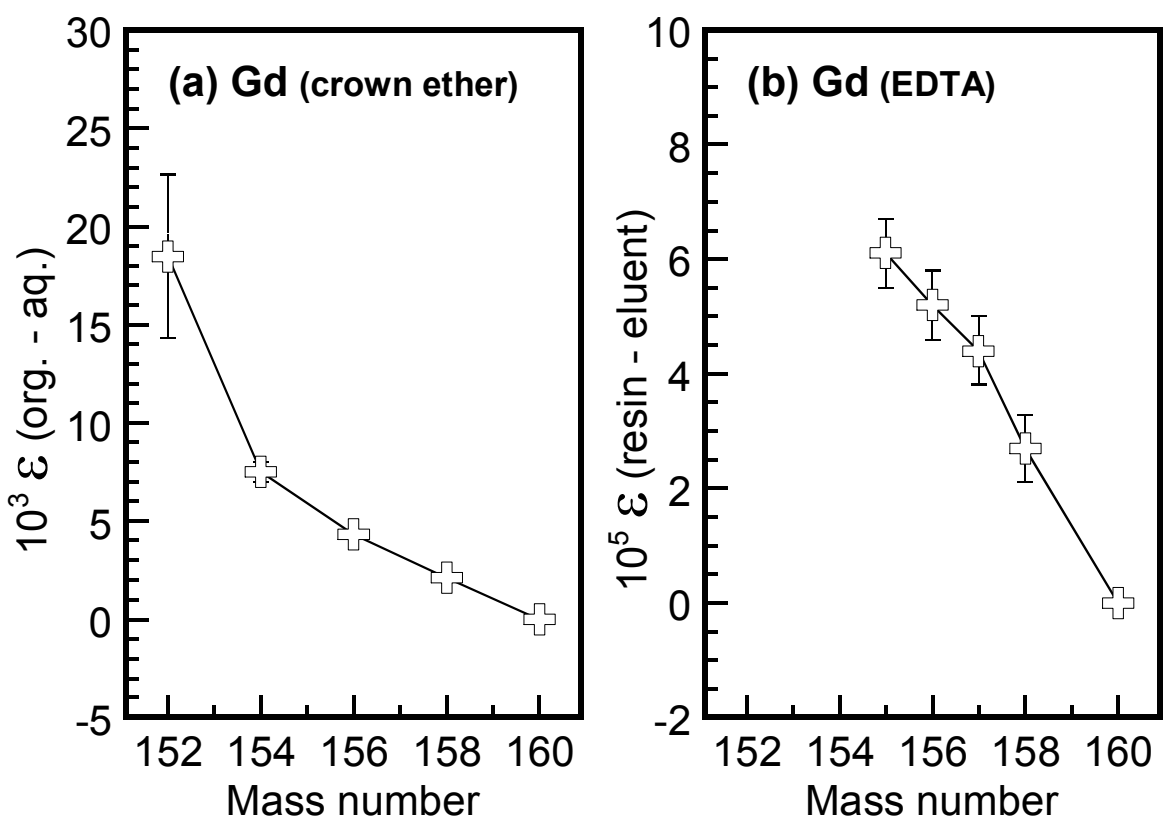


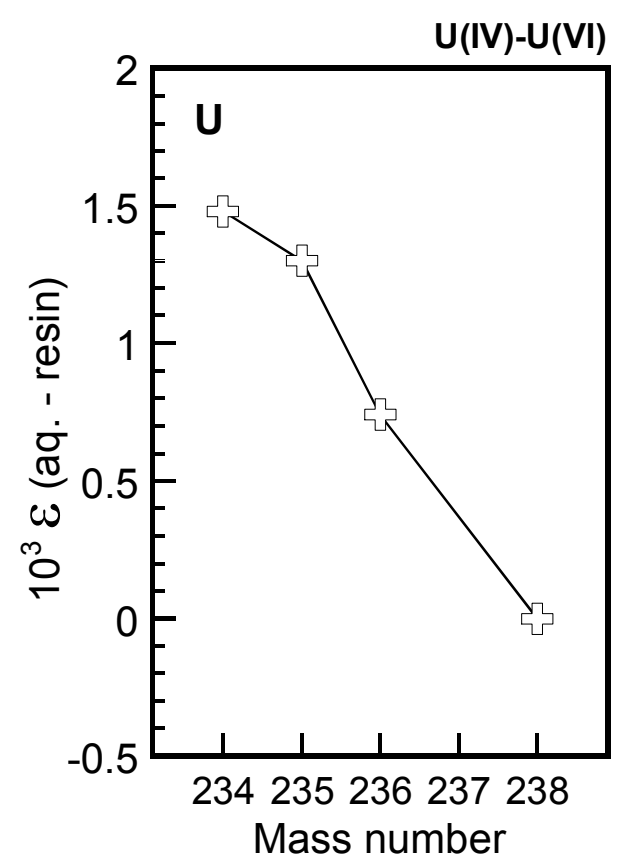

